\title{
Drogodependencias en el lugar de trabajo. Pautas generales de intervención desde la medicina del trabajo
}

\author{
Illicit drugs in the Workplace. General guidelines of intervention from the \\ Occupational Health
}

\author{
Carmen Otero Dorrego

\section{Correspondencia:} \\ Carmen Otero Dorrego \\ Servicio de Prevención de Riesgos Laborales. \\ Hospital Universitario de Móstoles \\ C/Río Júcar s/n \\ 28935 Móstoles (Madrid). España \\ Tfno.: + 34916648630 \\ E-mail: cotero.hmt|@salud.madrid.org
}

Servicio de Prevención de Riesgos Laborales. Hospital de Móstoles (Madrid). España.

Resumen

El abuso de drogas es un importante problema de salud pública, así como un grave problema laboral en los países industrializados. Las serias consecuencias laborales (menor rendimiento, aumento del número de accidentes, etc.) y la posibilidad de abordar el problema con éxito desde los servicios de salud laboral de las empresas, hacen necesarias la creación de políticas y programas de intervención. El objetivo general de todos estos programas es conseguir la rehabilitación personal y laboral de los trabajadores afectados. Otros objetivos secundarios son mejorar los índices de absentismo y accidentabilidad, establecer pautas generales de actuación de los médicos del trabajo para intervenir en las situaciones de abuso de drogas en el lugar de trabajo, así como favorecer la reincorporación laboral adecuada de los trabajadores que han seguido un programa de deshabituación.

En este artículo se hace una revisión de datos epidemiológicos, consecuencias laborales, personales y sociales, diferentes normas y recomendaciones internacionales y nacionales, así como de programas específicos de empresas nacionales y extranjeras en los diferentes sectores de producción. Por último, se describen las pautas generales de actuación de los médicos del trabajo de los servicios de salud laboral.

Las actuaciones del Médico del trabajo en el ámbito de la Prevención Primaria se dirigirán a la detección de factores de riesgo en el puesto de trabajo (evaluación de riesgos psicosociales y facilidad de acceso a drogas en el trabajo, entre otros) y factores individuales (detección precoz de trabajadores especialmente sensibles), aplicando medidas correctoras (formativas e informativas, adaptación de puestos de trabajo, etc.). El médico del trabajo también se ocupará de realizar un diagnóstico precoz (Prevención Secundaria) para tratamiento de desintoxicación y deshabituación a través de la red asistencial del Sistema Nacional de Salud. Y, por último, facilitará la rehabilitación laboral (Prevención Terciaria) favoreciendo la reincorporación laboral del trabajador con garantías de seguridad.

Palabras clave: drogas de abuso, lugar de trabajo, intervención, medicina del trabajo.

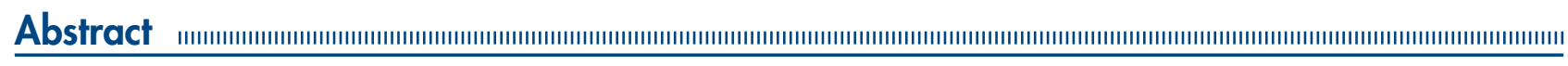

Drug abuse is an important problem of public health, as well as a serious labor problem in industrialized countries. The serious labor consequences (smaller yield, increase of the number of accidents, etc.) and the possibility of successfully approaching the problem from Occupational Health Services of companies, make the creation of politics and programs of intervention necessary. The overall goal of all these programs is to 
obtain the personal and labor rehabilitation of the affected workers. Other secondary targets are to improve the indices of absenteeism and accidentability, to establish general guidelines of performance of occupational health doctors to take part in the situations of drug abuse in the work place, as well as to favor the suitable labor restoration of workers who have followed a therapy program.

In this article we make a revision of epidemiologic data, labor, personal and social consequences, different norms and international and national recommendations, as well as of specific programs of national and foreign companies in the different sectors from production. Finally, the general guidelines of intervention from Occupational Health Physicians are described.

The performances of Occupational Health Physicians in the scope of Primary Prevention will be directed towards the detection of risk factors at work (evaluation of psycho-social risks and facility of access to drugs at work, among others) and individual factors (early detection of specially sensible workers), applying correction measures (training courses, job adaptations, etc). Occupational Health Physicians will also make early diagnosis (Secondary Prevention) for detox through the National Health System. Finally, they will facilitate labor rehabilitation (Tertiary Prevention) favoring labor restoration of the worker with security guarantees.

Key words: drug abuse, Workplace, intervention, Occupational Health. 


\section{INTRODUCCIÓN}

El consumo de drogas representa en la actualidad uno de los mayores problemas de salud pública en los países industrializados, que además, lejos de disminuir, se ha ido incrementando en los últimos años. Es un error asumir que el consumo abusivo de drogas afecta a sectores marginales de la sociedad, con alta tasa de desempleo. Todo lo contrario, es un problema que afecta a una gran parte de la población laboral activa, lo que ocasiona graves consecuencias en los lugares de trabajo: problemas de seguridad por accidentes debidos a la falta de atención y concentración en los trabajadores afectados, aumento del absentismo laboral, conflictividad laboral (disputas con jefes y compañeros), etc.

Aunque la adicción a drogas tiene una etiología multicausal, entre las diversas causas o factores contribuyentes también pueden contemplarse algunos aspectos psicosociales del trabajo (altas demandas de tarea, situaciones de estrés mantenido, etc.). El trabajador que consume de forma habitual drogas, en algún momento de su proceso patológico representará un riesgo personal hacia sí mismo o hacia terceras personas (según las tareas que tenga asignadas y su nivel de responsabilidad), sobre todo en situaciones adversas de mayor estrés. La Organización Internacional del Trabajo (OIT), desde hace ya casi dos décadas, ha reconocido los problemas que suponen el consumo de drogas y alcohol en cuanto problema de seguridad laboral y elevado coste para la producción, ya que suele tener como consecuencia absentismo, enfermedades y lesiones relacionadas con el trabajo ${ }^{1}$. En 1998 la OIT estimó que las lesiones relacionadas con drogas y alcohol suponían entre un 15 y un $30 \%$ del total de los accidentes relacionados con el trabajo ${ }^{2}$. La accidentabilidad laboral es tres veces superior en trabajadores con adicción a drogas y alcohol, un tercio de los accidentes laborales mortales están relacionados con el consumo de sustancias, la tasa de accidentes se duplica o triplica en estos trabajadores y también se triplican las bajas laborales y el absentismo. No es, pues, de extrañar que en todo el mundo se esté registrando un creciente interés por la aplicación de los programas de prevención, y concretamente los que están vinculados al lugar de trabajo.

En nuestro país, desde que en 1995 se aprobó la Ley de Prevención de Riesgos Laborales (LPRL), se establece la obligación o deber del empresario de protección de los trabajadores frente a los riesgos laborales (Art. 14.1, LPRL) ${ }^{3}$. En el caso de las drogodependencias de los trabajadores, existe mucha controversia, ya que si bien se trata de un problema social y personal que extralimita el ambiente laboral, las consecuencias del consumo y los efectos producidos en los trabajadores afectados (déficit de atención, etc.) pueden representar serios problemas de seguridad para sí mismos, para los demás trabajadores o para otras personas relacionadas con la empresa. Por este motivo, los empresarios muestran cada vez más interés por aplicar los programas preventivos en materia de drogodependencias a los lugares de trabajo, no sólo por política social de empresa hacia sus trabajadores, sino también por responsabilidad social. Evitar la accidentabilidad y mejorar la seguridad es una necesidad básica para la mayoría de las empresas, sobre todo en sectores de servicios con graves consecuencias de fallos de seguridad (por ejemplo: empresas de transporte de pasajeros ferroviarias o líneas de transporte aéreo, o en empresas de construcción, o incluso en profesiones como la medicina, en los que unos sentidos y una capacidad de juicio deteriorados pueden tener unas consecuencias fatales). Los controles de drogas en el lugar de trabajo (CDLT) ${ }^{4}$ constituyen un fenómeno relativamente nuevo iniciado en las grandes multinacionales y difundido por ellas en casi todos los países. Sin embargo, la polémica rodea a los CDLT, considerando conflictos como el derecho a la intimidad, a la responsabilidad social y a la responsabilidad potencial de los empresarios, así como las dificultades en la interpretación de los resultados. En cualquier caso, los CDLT han demostrado una gran utilidad para el control de las drogodependencias en las empresas, siempre que sólo sean una herramienta más de un programa integral de prevención de drogodependencias, encuadrado en el marco de una Política de Prevención de Drogas en la empresa, en la que deben intervenir tanto el empresario, como los agentes sociales (sindicatos, delegados de prevención), así como los profesionales sanitarios de los Servicios de Prevención, garantizando la 
confidencialidad y el derecho de intimidad del enfermo, así como el "deber de asistencia" de la organización.

En este contexto, la intervención del Médico del Trabajo es básica, tanto si existe en la empresa una Política de Prevención de Drogas (en este caso las actuaciones del médico del trabajo estarán protocolizadas), como si no. El problema del trabajador adicto a drogas entrará en el ámbito de los riesgos laborales en el momento en que se considere (y se documente) que dicho trabajador puede representar un problema de seguridad, por ser un riesgo para sí mismo, para los demás trabajadores o para otras personas relacionadas con la empresa, (Art. $22 \mathrm{LPRL}^{3}$ ). El Médico del Trabajo deberá desarrollar su actividad:

1. Detectando factores de riesgo (Prevención Primaria) y actuando sobre los mismos: tanto factores de riesgo colectivos en la organización y en el puesto de trabajo (Evaluación de riesgos psicosociales y de puestos de trabajo de fácil acceso a psicofármacos, Programas de formación, etc.) como factores individuales personales (detección precoz de trabajadores especialmente sensibles (TES), según Art. $25 \mathrm{LPRL}^{3}$.

2. Realizando el diagnóstico precoz en los trabajadores consumidores y/o adictos a sustancias (Prevención Secundaria) y la derivación al SNS para tratamiento de desintoxicación y deshabituación.

3. Y por último, facilitando la rehabilitación laboral (Prevención Terciaria) favoreciendo la reincorporación laboral del trabajador tras tratamiento de deshabituación, con garantías de seguridad.

\section{ALCANCE DEL PROBLEMA}

La elevada prevalencia del consumo de drogas y/o alcohol entre la población trabajadora convierte estos consumos en un problema de gran magnitud ${ }^{5}$. Estas elevadas prevalencias de consumo observadas en nuestro país son similares a las que presentan el resto de los países industrializados europeos ${ }^{6,7,8}$. El Observatorio Español Sobre Drogas lleva a cabo una encuesta bianual desde 1995, la Encuesta Domiciliaria sobre Alcohol y Drogas en España (EDADES). En el período 2007-2008 se incluyó un módulo específico en la población laboral, cuyo objetivo prioritario, en el marco de la Estrategia Nacional sobre Drogas para el período 2009-2016 ${ }^{\circ}$, es ayudar a identificar prioridades para la acción preventiva en el campo de la salud laboral. Se concluyó que, globalmente, la prevalencia de consumo de drogas en la población laboral es similar a la encontrada e la población general, las sustancias más consumidas son las legales (tabaco y alcohol) y la droga ilegal con mayor prevalencia de consumo es el cannabis, seguido de la cocaína en polvo. En realidad, la prevalencia tiende a ser algo más elevada para todas las drogas ilegales en la población laboral que en la general (Tabla I), salvo para los consumos de tranquilizantes y somníferos (en grupos de edad de 35 a 64 años), que es más bajo en la población laboral ${ }^{6}$.

La prevalencia de consumo de cannabis en el último año anterior a la encuesta (2008) entre la población laboral fue de un $13.3 \%$ en los hombres y de un $7.3 \%$ en las mujeres, admitiendo un consumo diario un $1,8 \%$ de los hombres y un $0,7 \%$ de las mujeres. En la tabla II se detallan los porcentajes obtenidos según las variables laborales. Se obtuvo un patrón de consumidor de cannabis característico: hombre joven, en paro, con un nivel de estudios mayor que primario y trabajador del sector de la construcción o la hostelería ${ }^{6}$.

La cocaína es la segunda droga ilegal más consumida en España. La prevalencia de consumo de cocaína en polvo en el último año anterior a la encuesta (2008) entre la población laboral fue de un $4.7 \%$ en los hombres y de un $1.8 \%$ en las mujeres, admitiendo su consumo en el último mes un $2,6 \%$ de los hombres y un $0,9 \%$ de las mujeres. En la tabla III se detallan los porcentajes obtenidos según las variables laborales. Se observó una prevalencia de consumo más elevada en hombres, entre 16 a 34 años de edad, y más elevada entre parados que entre empleados, en sectores de construcción y hostelería. En las mujeres, las cifras más elevadas se dan en el sector del transporte/almacenamiento/comunicación. 
Respecto a otras sustancias, la prevalencia del consumo de éxtasis en el último mes fue de $1.7 \%$ en hombres y $0.8 \%$ en mujeres, la prevalencia del consumo de anfetaminas en el último mes fue de un 0.4 en los hombres y un 0.2 en las mujeres, sólo un $0.8 \%$ de los hombres reconocieron haber consumido alucinógenos en el último mes y sólo un $0.2 \%$ de los hombres reconoció el consumo de heroína en el último año (la mayoría parados con experiencia laboral) ${ }^{6}$.

Tabla I. Porcentaje de la población laboral y general que ha consumido diferentes sustancias psicoactivas en los últimos 12 meses (salvo tabaco diario). España 2008.

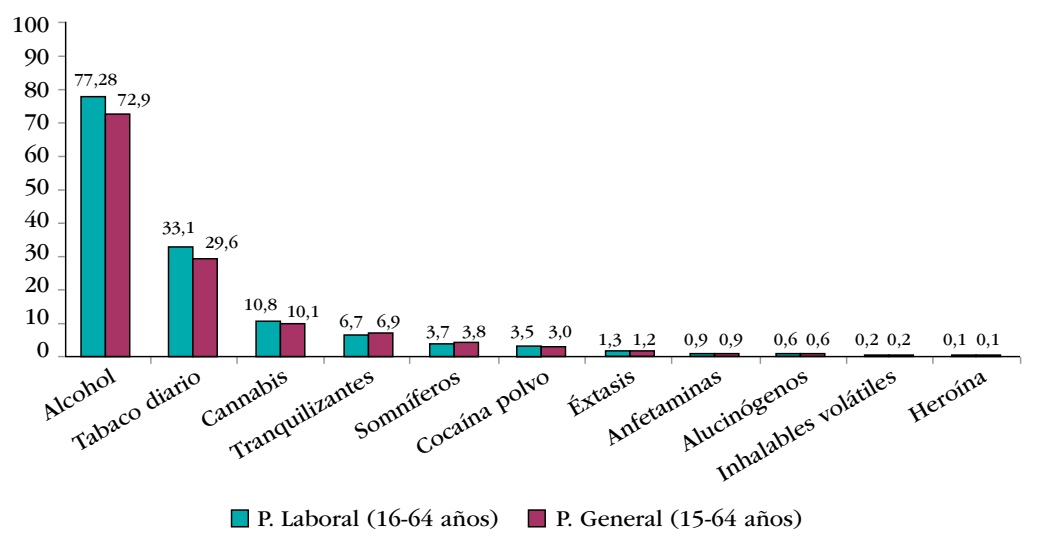

Fuente: Encuesta 2007-2008 sobre consumo de sustancias psicoactivas en el ámbito laboral en España. EDADES. Observatorio Español sobre Drogas.

Tabla II. Porcentaje de población laboral que ha consumido Cannabis en los últimos 12 meses según las variables laborales y distribuido por sexo. España 2008

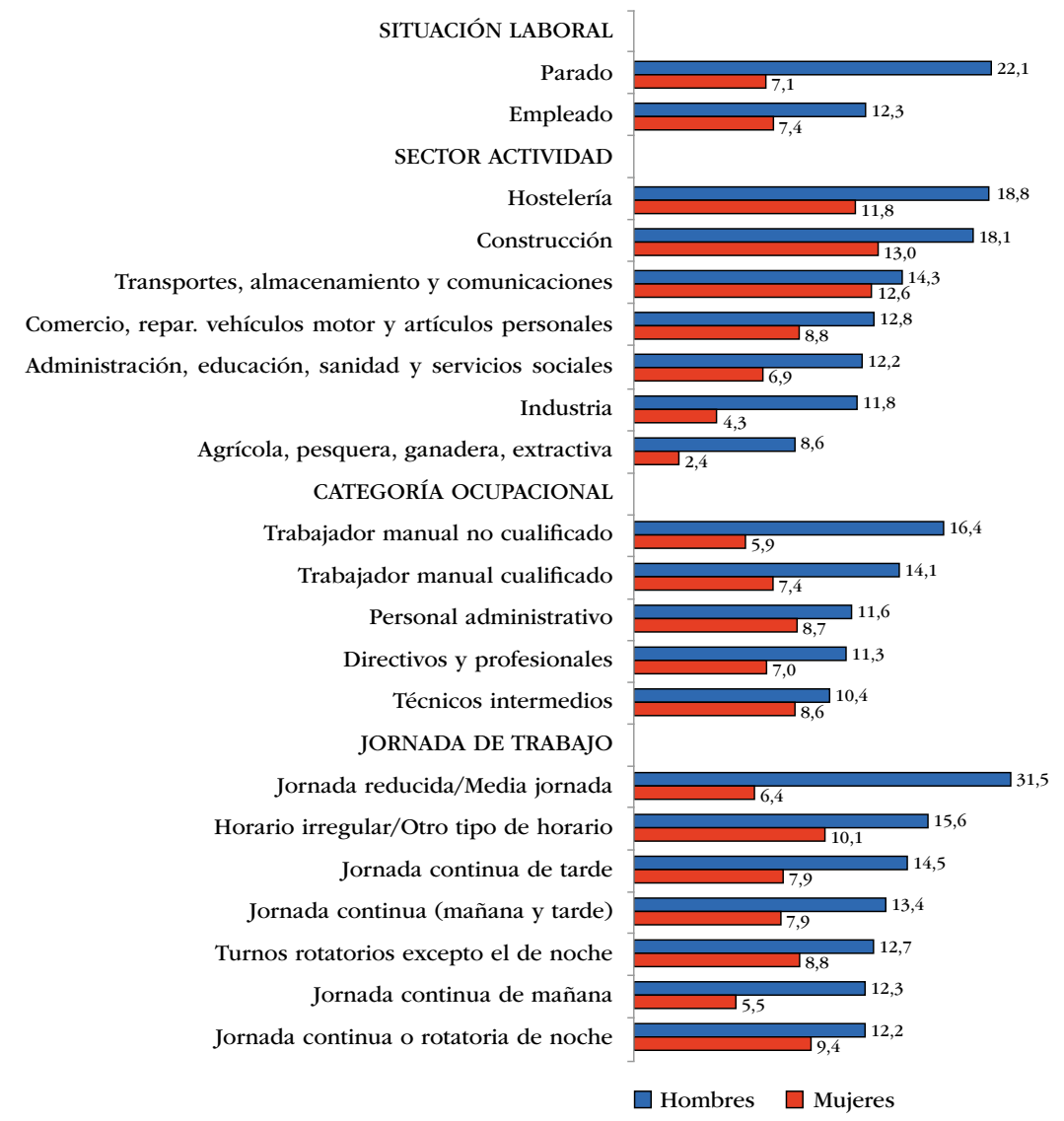

Fuente: Encuesta 2007-2008 sobre consumo de sustancias psicoactivas en el ámbito laboral en España. EDADES. Observatorio Español sobre Drogas. 
Tabla III. Porcentaje de población laboral que ha consumido Cocaina en los últimos 12 meses según las variables laborales y distribuido por sexo. España 2008.

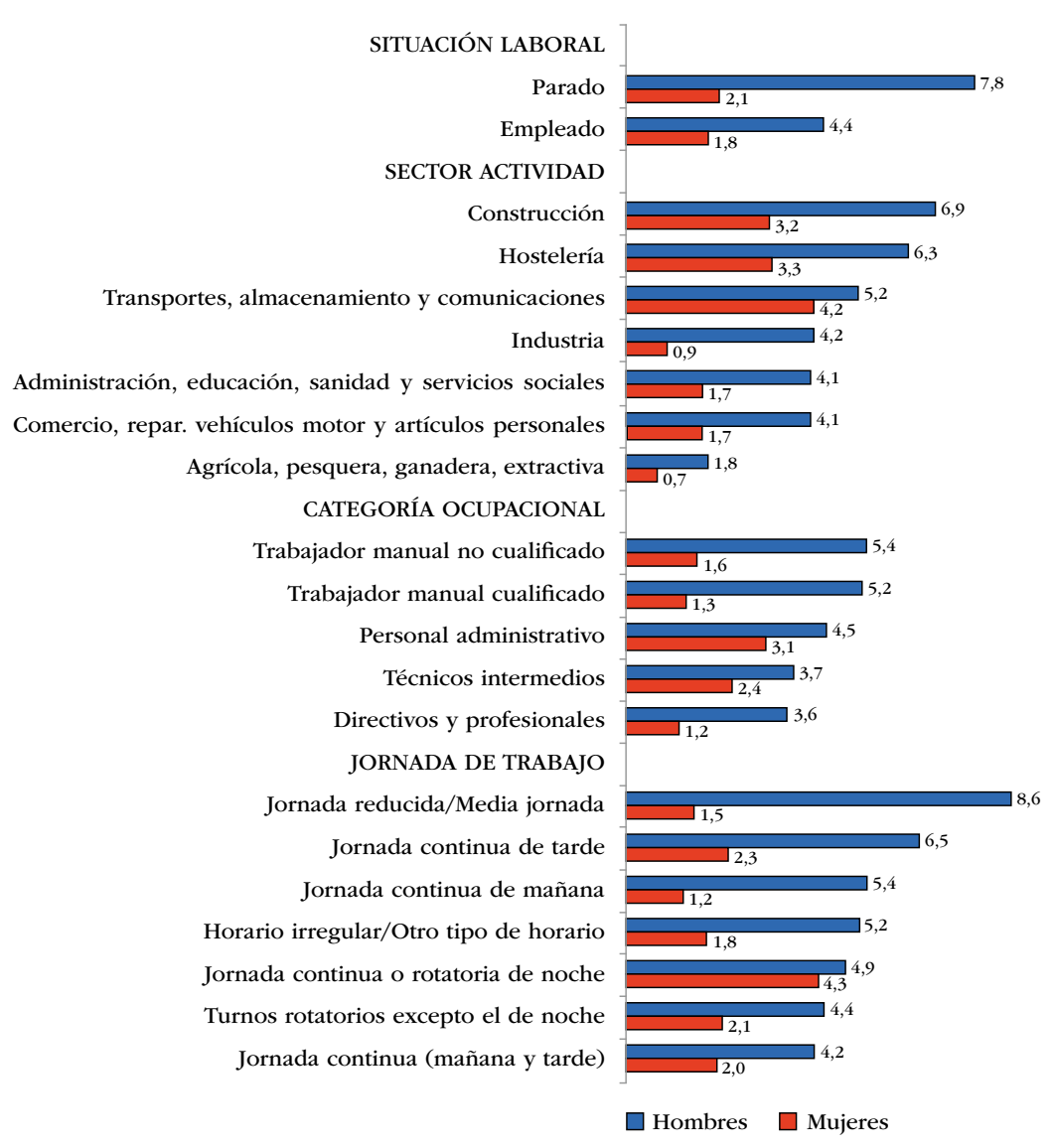

Fuente: Encuesta 2007-2008 sobre consumo de sustancias psicoactivas en el ámbito laboral en España. EDADES. Observatorio Español sobre Drogas.

Según concluye la encuesta 2007-2008, las prevalencias de consumo son mayores, para todas las sustancias consideradas, en el grupo de hombres parados frente al grupo de los que tienen empleo. Solo el consumo de hipnosedantes es la única sustancia que es consumida por una mayor proporción de mujeres que de hombres, y en grupos de mayor edad ( 35 a 64 años), también asociado en mayor medida al desempleo. En cuanto al tipo de jornada laboral, la mayor proporción de consumidores, entre los hombres, realizan jornadas reducidas o media jornada. En las mujeres trabajadoras, las mayores prevalencias de consumo se observan en aquellas que tienen jornada continua o turnos rotatorios. Al preguntar por los riesgos de seguridad percibidos, se observan mayores prevalencias de consumo de hipnosedantes, cannabis y cocaína entre los trabajadores de ambos sexos que dicen realizar trabajos de mayor peligrosidad y/o penosidad. El consumo de drogas ilegales también muestra mayores prevalencias entre los trabajadores de ambos sexos que refieren estar expuestos a los factores de riesgo psicosociales ${ }^{6}$.

Los datos que nos suministra la encuesta son muy valiosos para hacernos una idea descriptiva del problema en nuestro país, sin embargo hay que resaltar una cuestión importante: se ha encuestado a población en edad laboral (activa o parada) que refieren datos relativos a un consumo más asociado al tiempo de ocio o inactividad laboral (parados, trabajadores con jornadas reducidas, etc.), pero no es representativo del consumo en el lugar y/o tiempo de trabajo. No obstante los consumidores habituales de drogas, aún en su tiempo de ocio, pueden manifestar alteraciones psicofísicas (déficit de atención, cansancio, ansiedad ) que también repercuten en la productividad (menor rendimiento, mayor absentismo) y en la seguridad laboral (aumento de accidentes laborales). Otro problema que puede generar controversia es el consumo esporádico por parte de algunos 
trabajadores, que puede generarles problemas laborales en empresas con programas de control de drogas a sus trabajadores. Es conveniente diferenciar los patrones de consumo que se puedan presentar, porque la intervención se tiene que personalizar.

\section{DEFINICIONES}

Aunque se pueden encontrar múltiples definiciones de "droga ilícita”, la Organización Mundial de la Salud (OMS) establece que se trata de cualquier sustancia, terapéutica o no, introducida en el cuerpo por cualquier mecanismo, capaz de actuar sobre el sistema nervioso central (SNC) del individuo, hasta provocar en él una reacción física o intelectual, la experimentación de nuevas sensaciones o la modificación de su estado psíquico. Esta modificación, condicionada por los efectos inmediatos (psicoactivos) o persistentes (crónicos), predispone a una reiteración continuada en el uso del producto ${ }^{10}$. En realidad, hace referencia a las consecuencias biológicas que sufre un organismo, pero además de las consecuencias individuales se deben contemplar también las consecuencias sociales. Se trata de un problema personal (efectos nocivos para la propia salud) y social (afectación del bienestar social) ${ }^{11}$. En este sentido se pueden considerar "drogas ilícitas" a "todas aquellas sustancias que, introducidas en un organismo vivo, pueden modificar una o más funciones de éste, siendo capaces de generar dependencia, provocar cambios en la conducta y efectos nocivos para la salud y el bienestar social" ${ }^{12}$.

Tabla IV. Clasificación de las drogas según su mecanismo de acción sobre el SNC

\begin{tabular}{|c|c|c|c|}
\hline \multirow{2}{*}{ Depresores } & \multicolumn{2}{|c|}{ Estimulantes } & \multirow{2}{*}{ Perturbadoras } \\
\hline & Mayores & Menores & \\
\hline $\begin{array}{l}\text { Opiáceos (heroína, } \\
\text { morfina...) } \\
\text { FORMAS DE CONSUMO: } \\
\text { - Dependencia psicológica y } \\
\text { física intensa a un ritmo muy } \\
\text { acelerado. } \\
\text { - Heroína: polvo blanco o ma- } \\
\text { rrón para fumar o inyectar. } \\
\text { También sublingual, inhala- } \\
\text { da, etc. } \\
\text { EFECTOS PSICOLÓGICOS: } \\
\text { - Apatía, sedación, paz, euforia, } \\
\text { somnolencia. Efectos sedan- } \\
\text { tes e hipnóticos mayores con } \\
\text { fentanilo. } \\
\text { - S. abstinencia (mono) muy } \\
\text { potente. } \\
\text { EFECTOS FISIOLÓGICOS: } \\
\text { - Analgesia, inhibidor de la } \\
\text { tos, respiratorio y del vómito } \\
\text { (SNC), miosis. Sequedad de } \\
\text { mucosas, sensación de calor } \\
\text { y disminución de la tempe- } \\
\text { ratura corporal. Disminución } \\
\text { de tensión arterial. } \\
\text { - Alcohol } \\
\text { Tranquilizantes } \\
\text { (benzodiacepinas) } \\
\text { Hipnoticos } \\
\text { (barbitúricos y no } \\
\text { barbitúricos }\end{array}$ & $\begin{array}{l}\text { Cocaína } \\
\text { FORMAS DE CONSUMO: } \\
\text { - Hoja mascada o en infusión. } \\
\text { - Pasta de coca (fumada mez- } \\
\text { clada con tabaco o cannabis). } \\
\text { - Hidrocioruro de cocaína (pol- } \\
\text { vo) inhalado, también se fue- } \\
\text { ma e inyecta. } \\
\text { - Pasta base inhalada o fumada. } \\
\text { - Crack (se fuma). } \\
\text { - Mezclas con heroína. } \\
\text { EFECTOS PSICOLÓGICOS: } \\
\text { - Euforia, locuacidad, aumento } \\
\text { de la sociabilidad, acelera- } \\
\text { ción mental, hiperactividad, } \\
\text { aumento del deseo sexual. } \\
\text { EFECTOS FISIOLÓGICOS: } \\
\text { - Disminución de la fatiga, re- } \\
\text { ducción del sueño, inhibición } \\
\text { del apetito, aumento de la } \\
\text { tensión arterial (HTA). } \\
\text { - Anfetaminas } \\
\text { FORMAS DE CONSUMO: } \\
\text { - En pastillas o comprimidos } \\
\text { suelen ser un componente } \\
\text { de otras drogas (drogas de } \\
\text { diseño). } \\
\text { EFECTOS PSICOLÓGICOS: } \\
\text { - Agitación, euforia, sensación } \\
\text { de autoestima aumentada, } \\
\text { verborrea, alerta y vigilancia, } \\
\text { agresividad. } \\
\text { EFECTOS FISIOLÓGICOS: } \\
\text { - Falta de apetito, taquicardia, } \\
\text { sequedad de boca, sudora- } \\
\text { ción, aumento de presión ar- } \\
\text { terial, contracción mandibular. }\end{array}$ & $\begin{array}{l}\text { - Nicotina } \\
\text { - Xantinas } \\
\text { - Inhalantes (acetona, } \\
\text { bencinas, etc.) }\end{array}$ & 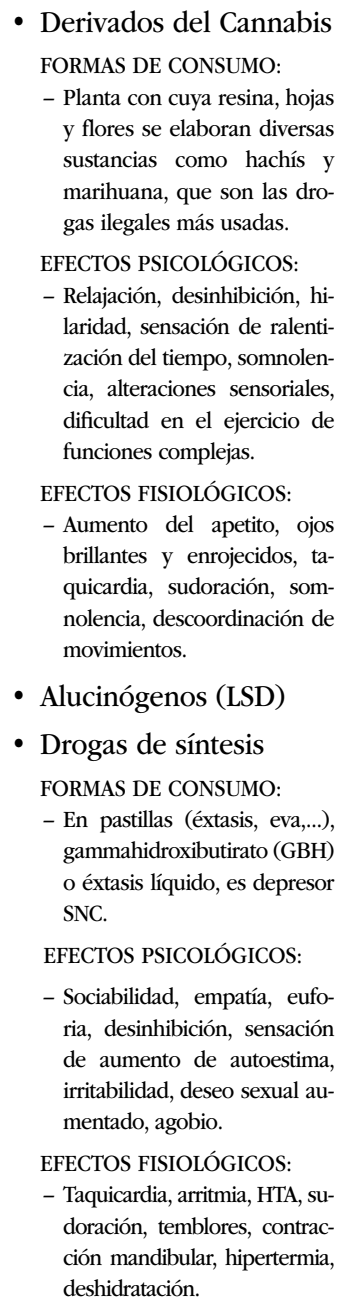 \\
\hline
\end{tabular}


Tienen consideración de drogas el alcohol y el tabaco ("drogas legales o institucionalizadas"), las sustancias psicoactivas y cualquier otra sustancia que provoque un trastorno adictivo, que es un patrón desadaptativo de comportamiento, que provoca un trastorno psíquico, físico o de ambos tipos, por abuso de sustancias o conducta determinada, repercutiendo negativamente en las esferas psicológica, física y social de la persona y su entorno. La drogodependencia es un tipo especial de trastorno adictivo que se caracteriza por modificaciones en el comportamiento y un impulso irreprimible por consumir una droga en forma continuada o periódica, a fin de experimentar sus efectos psíquicos y físicos y, a veces, para evitar el malestar producido por su privación" ${ }^{11,12}$.

Pueden clasificarse por su grado de peligrosidad (clasificación que hace la OMS), pero lo habitual es encontrar clasificaciones de las drogas por grupos según la acción que tienen sobre el sistema nervioso central (SNC) ${ }^{10,13}$, según se representa en la Tabla IV.

\section{ANÁLISIS DE CONSECUENCIAS}

Las consecuencias del consumo abusivo de drogas pueden generar responsabilidades personales (para el propio consumidor), sociales (problemas de inseguridad ciudadana, delitos asociados al narcotráfico, etc) y laborales (accidentabilidad, absentismo, etc). En ocasiones se pueden producir daños a otras personas (daños a terceros), derivados unas veces de accidentes ocasionados por un consumidor con un estado psicofísico alterado, sin intencionalidad, o actos delictivos cometidos con intención de conseguir dinero para el consumo (robos, inseguridad ciudadana, etc.).

Por motivos de responsabilidad social, se han creado organismos encargados del control internacional de las drogas de abuso, como la Junta Internacional de Fiscalización de Estupefacientes (JIFE), o el Convenio de Viena (Convenio sobre sustancias psicotrópicas, 1971). España está representada en ambos, si bien, en nuestro país el órgano más representativo para el control de drogas de abuso es el Plan Nacional de Drogas (PND) ${ }^{14}$, que se encarga de coordinar y potenciar las políticas que se llevan a cabo desde las diferentes Administraciones e impulsar las reformas legales ${ }^{10,14}$. La legislación española en materia de control de drogas de abuso es amplia (multitud de normas autonómicas) y compleja, aunque siguiendo siempre las directrices que marcan los convenios internacionales.

En materia de responsabilidad penal, no se considera delito el consumo de drogas, pero si la tenencia que se dedique al tráfico (Art. 368 Código Penal (CP)). Desde la última reforma del CP, en materia de seguridad vial, se contempla la pena de prisión o multa para aquel que conduzca un vehículo a motor bajo la influencia de drogas tóxicas, estupefacientes, sustancias psicotrópicas o de bebidas alcohólicas (es importante contemplar este problema en casos de accidentes de trafico con relación laboral: accidentes "in itinere" o accidentes "in mision"). En cualquier caso, El Código Penal considera que la drogodependencia (en caso de adicciones graves) es una circunstancia atenuante cuando se han cometido actos delictivos (Art. 21.2 CP) ${ }^{10,11,15}$. En caso de adicciones graves y con carácter habitual, siempre que impidan a la persona gobernarse por sí misma, se pude considerar la incapacitación del adicto según la norma civil (Art. 200 Código Civil) ${ }^{10}$.

Sin embargo, el consumo o tenencia ilícita de drogas (aunque no se dedique para el tráfico de las mismas) sí que puede dar lugar a responsabilidad administrativa con imposición de sanciones (administrativas y disciplinarias) cuando se realice en lugares públicos o cuando dicho consumo sea tolerado por parte de los responsables de los locales o establecimientos públicos (ambas situaciones se consideran infracciones graves según la Ley de Protección de la Seguridad Ciudadana, Art. 25 y 23.i, respectivamente) ${ }^{11,16}$.

En el ámbito laboral las repercusiones del consumo de drogas pueden ser muy graves. La OIT estima que las lesiones relacionadas con drogas y alcohol suponen entre un 15 y un $30 \%$ del total de los accidentes relacionados con el trabajo ${ }^{2}$. Es decir, más de una cuarta parte del total de accidentes laborales ocurren en trabajadores que se encuentran bajo los efectos de alcohol y/o drogas, causándose lesiones a sí mismos o a otros. El absentismo 
entre los trabajadores consumidores de drogas es 2 a 3 veces mayor, y el coste de las bajas por enfermedad que generan también es 3 veces superior respecto al resto de trabajadores 5 .

El consumo abusivo de drogas también se sanciona en el Derecho Laboral. El Estatuto de los Trabajadores (ET) contempla el despido disciplinario por este motivo, siempre y cuando sean conductas habituales y tengan repercusión negativa en el trabajo (Art. 54.f) ${ }^{11}{ }^{17}$. Sin embargo, los despidos disciplinarios causados por consumo de drogas suelen recurrirse, sobre todo si no hay preceptos al respecto en Convenio Colectivo, y no se puede demostrar que el consumo sea habitual, aunque sí se demuestre la repercusión negativa en el trabajo. Esta línea represora no contribuye a la solución del problema, ya que la drogodependencia es una enfermedad ${ }^{11,18}$ y como tal hay que abordarla. Según la OMS, en el nuevo plan de acción de la UE se destaca la prevención en entornos específicos, como por ejemplo el lugar de trabajo. El mayor hincapié en la prevención específica puede ser un contrapeso a la tendencia general de reducción de la gravedad de las penas para los consumidores de droga, quizá debido a la preocupación por la prevalencia y frecuencia del consumo de drogas en la $\mathrm{UE}^{19}$. Como parte de una estrategia internacional amplia para reducir la demanda de drogas y alcohol, los objetivos de la acción de la OIT en este terreno, consisten en una estrategia doble: prevención en el lugar de trabajo y rehabilitación en la comunidad ${ }^{2}$.

La Estrategia Nacional sobre Drogas para el período 2009-2016 instituye en España el modelo de prevención dentro de los programas de salud laboral, y la Ley de Prevención de Riesgos Laborales (LPRL), establece la obligación o deber del empresario de protección de los trabajadores frente a los riesgos laborales (Art. 14.1, LPRL) ${ }^{3}$. En el caso de las drogodependencias de los trabajadores, aunque se trate de un problema social y personal que extralimita el ambiente laboral, se debe contemplar la prevención no sólo del consumo, sino de las consecuencias del consumo, ya que el trabajador adicto pueden ocasionar accidentes muy graves para sí mismo y para otras personas en la empresa, además de múltiples daños colaterales.

\section{POLIITICAS DE PREVENCIÓN EN RELACIÓN CON LAS DROGAS EN EL TRABAJO}

Las administraciones sanitarias promocionan el desarrollo de planes de prevención en las empresas y programas específicos de salud laboral que mejoren la situación de los trabajadores en relación con el consumo de drogas ${ }^{5}$. Las grandes empresas, sobre todo en el sector del transporte de pasajeros, se suman a esta iniciativa, porque comprenden la importancia que tiene la prevención para evitar los enormes costes directos e indirectos que el consumo de drogas puede provocar. Aunque es muy difícil estimar el coste por abuso de drogas en una empresa ${ }^{13,20}$ se contemplan:

1. Costes Directos:

- Coste del programa de prevención y ayuda al empleado (horas de recursos humanos empleados para formación, información y supervisión, coste de pruebas analíticas y tratamiento adecuado de las muestras, costes de laboratorio).

2. Costes Indirectos:

- Coste de atención sanitaria por enfermedad o accidente.

- Coste de incapacidad temporal u otro tipo de incapacidad (absentismo).

- Coste de rotación de puestos o contratación por sustitución de bajas.

- Coste por caída de la productividad.

- Coste incurrido cuando la imagen de la empresa haya sufrido perjuicio.

- Coste por supervisión del trabajo de operarios que no rinden en su puesto.

- Coste por daños a equipos o productos.

- Coste por responsabilidad legal.

- Coste por baja moral en la empresa y aumento de la conflictividad interna. 
- Costes por malas decisiones tomadas por abuso de drogas (incidentes, mala calidad del producto).

- Los costes del abuso de drogas también incluirían a otros miembros del grupo familiar del adicto que no son consumidores (son más generadores de bajas laborales que el resto de los trabajadores).

Un Programa de Prevención efectivo que "ahorre" evitando los enormes costes que puede suponer la presencia de drogas en el trabajo siempre resultará rentable para la empresa. El Servicio de Correos de EEUU constató que el ahorro en cinco años del programa de filtrado de los aspirantes con pruebas positivas hubiera ascendido a 105 millones de dólares ${ }^{20}$. Al plantearse establecer un Programa de prevención, se deben considerar tres aspectos: que los trabajadores son una parte vital de todo negocio, que puede ser más efectivo ofrecer ayuda para problemas personales que adoptar medidas disciplinarias contra los trabajadores, y que los trabajadores recuperados se convierten en personas comprometidas y leales a la empresa ${ }^{20}$.

Aunque es básica la predisposición de la Dirección de la empresa para iniciar estas estrategias preventivas, que se dirigen, no sólo a evitar el consumo de drogas por parte de los trabajadores, sino también a evitar que se produzcan los efectos nocivos que causa este consumo, se deben pactar entre empresa y Comité de Empresa (incluirlo en Convenio Colectivo). Lo primero es establecer una Política de Prevención de Drogas en el lugar de trabajo, dándole difusión entre los trabajadores. En el seno del Comité de Empresa y Comité de Seguridad y Salud se pactará la Planificación de la Acción Preventiva: planificación de un Programa de Prevención de Drogas y un Protocolo de actuación. Debe estar consensuado entre la empresa y los representantes de los trabajadores, y estará integrado en la Política de la Salud Laboral (Figura 1). Existen múltiples ejemplos en el panorama nacional ${ }^{13,21-25}$, no obstante, siempre se tratará de un plan concreto y específico para cada empresa. Un Plan de Prevención de drogas en el trabajo es un conjunto de actuaciones realizadas en el lugar de trabajo, encaminadas a prevenir, reducir o paliar los efectos asociados al consumo de las drogas. Las características generales que deben cumplir $^{24}$ se detallan en la Tabla V.

Figura 1. Agentes implicados en la Política de prevención de drogas en el trabajo

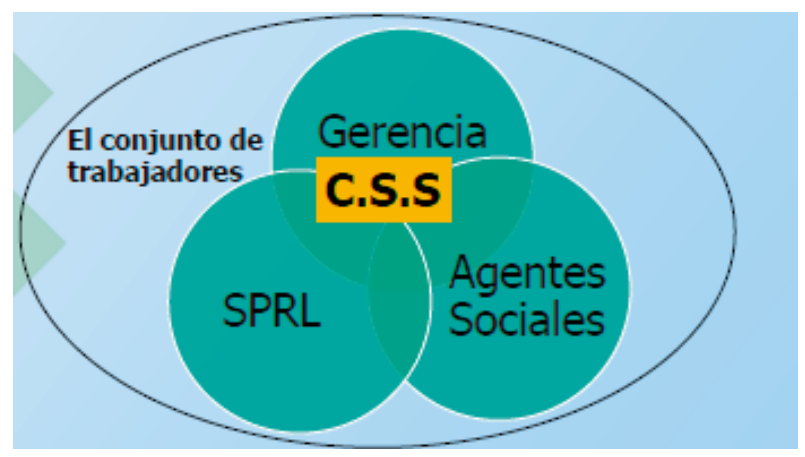

Los trabajadores acceden al plan de prevención de drogas en el trabajo bien por autoderivación, o bien por derivación de supervisores y compañeros. Si en la empresa se implanta un programa de control de drogas en el lugar de trabajo (CDLT) ${ }^{4,20}$, pactado en Comité de empresa y previsto en Convenio Colectivo, los resultados positivos se derivarían, con garantías de confidencialidad y con el consentimiento del trabajador, al plan de prevención de drogas, para tratamiento y posterior reincorporación. Los programas de CDLT no son voluntarios, siempre que contemplen el riesgo objetivable a sí mismo o a terceros (Art. 22 LPRL) que pueda generar un problema de seguridad, y su protocolización debe consensuarse en el seno del Comité de Seguridad y Salud. Aún así, este programa de CDLT debe tener un objetivo preventivo y no punitivo, se debe contemplar en los protocolos médicos de vigilancia de la salud laboral específicos para los riesgos, y debe estar integrado dentro del marco general de la política de drogas de la empresa, en la que se garantice que su objetivo no es perseguir a los adictos, sino contribuir a mejorar las condiciones de 
seguridad y salud en le empresa ${ }^{4,5,21-25}$. Los CDLT han demostrado una gran utilidad para el control de las drogodependencias en las empresas, siempre que sólo sean una herramienta más de un programa integral de prevención de drogodependencias, encuadrado en el marco de una Política de Prevención de Drogas en la empresa, en la que deben implicarse la Dirección, los representantes de los trabajadores (sindicatos y delegados de prevención), y los médicos del trabajo de los Servicios de Prevención, garantizando la confidencialidad y el derecho de intimidad del enfermo, así como el "deber de asistencia" de la organización y el compromiso de reincorporación laboral al puesto de trabajo tras el tratamiento.

Tabla V. Características de los Planes de Prevención de Drogas en el lugar de Trabajo

\begin{tabular}{ll}
\hline Concepto & Integrado \\
- Es, un conjunto de actuaciones realizadas en el lugar & - Enfocado desde las salud laboral. \\
de trabajo, encaminadas a prevenir, reducir o paIiar & \\
los efectos asociados al consumo de las drogas. & \\
Concreto & Confidencialidad \\
- Específico en cada empresa. & - No revelar la identidad de los trabajadores tratados. \\
& - Sólo utilizar los datos para fines terapeúticos. \\
Pactado & Gratuito \\
- Entre empresa y comité de empresa. & - Los costes serán a cargo de la empresa. \\
- Incluido en el convenio colectivo. & \\
Participativo & Voluntario \\
- Con representante de los trabajadores. & - Ningún trabajador se verá obligado a participar. \\
- Delegados de prevención. & \\
Total e integral & No sancionador \\
- Dirigido a todos los trabajadores. & - No tiene como objetivo ejercer un control discipli- \\
- Actúa no sólo sobre los hábitos, sino también sobre & nario sobre los trabajadores. \\
las consecuencia. & - Las enfermedades se "tratan" no se "castigan". \\
\hline
\end{tabular}

Tomado de Prevención de adicciones en los trabajadores de instituciones penitenciarias. Secretaría de salud laboral de UGT (2010) ${ }^{24}$

En España, el problema que se nos plantea es que muy pocas empresas disponen de Políticas de Prevención frente a las drogas, sólo empresas multinacionales y grandes empresas del sector servicios, construcción o transporte de pasajeros (FCC, RENFE, Iberia, por nombrar algunos ejemplos). La realidad es que la mayoría de las empresas españolas son lo que se conoce como Pequeña y Mediana Empresa (PYME), sin recursos suficientes o medios adecuados para la identificación precoz de trabajadores en situación de riesgo de drogodependencia. Según el Directorio Central de Empresas (DIRCE), a 1 de enero del año 2009 había en España 3.350.972 PYME (empresas comprendidas entre 0 y 249 asalariados). Es decir, el 99,88 por ciento de las 3.350 .972 empresas que conforman el censo, excluida la agricultura y la pesca ${ }^{26}$. La mayoría de estas empresas no han establecido ningún programa ni protocolo específico frente a las drogas. En general, no son conscientes del problema hasta que se produce una situación crítica ${ }^{5}$ (trabajadores con alteraciones del comportamiento bajo los efectos de las drogas o accidentes graves provocados por el consumo de drogas) y la toma de decisiones suele se punitiva (sanciones y medidas disciplinarias), cuando, hasta entonces, todos los que rodeaban al trabajador adicto habían intentado "no ver" el problema. Algunas confederaciones de empresarios, como la Confederación Empresarial Vasca (CONFEBASK) ${ }^{21}$, preocupados por estas situaciones y buscando una ayuda a la toma de decisiones, han elaborado documentos Guía para abordar el problema en las pequeñas empresas. Básicamente, proponen un "Protocolo de actuación ante un trabajador que se encuentra bajo los efectos de alcohol o drogas en el trabajo" (Figura 2), que finaliza en la visita al "servicio médico". El problema sólo se ha trasladado al médico del Trabajo del 
servicio de prevención [(ya sea propio (SPP), o en la mayoría de los casos, ajeno (SPA)] ¿Y cuál puede y debe ser la actuación del Medico del Trabajo en estas situaciones?

\section{ACTUACIÓN DEL MÉDICO DEL TRABAJO}

"El empresario garantizará a los trabajadores a su servicio la vigilancia periódica de su estado de salud en función de los riesgos inherentes al trabajo. Esta vigilancia sólo podrá llevarse a cabo cuando el trabajador preste su consentimiento. De este carácter voluntario sólo se exceptuarán, previo informe de los representantes de los trabajadores, los supuestos en los que la realización de los reconocimientos sea imprescindible para evaluar los efectos de las condiciones de trabajo sobre la salud de los trabajadores o para verificar si el estado de salud del trabajador puede constituir un peligro para el mismo, para los demás trabajadores o para otras personas relacionadas con la empresa o cuando así esté establecido en una disposición legal en relación con la protección de riesgos específicos y actividades de especial peligrosidad [...]" (Art. 22 LPRL $^{3}$ ).

Todos los reconocimientos médicos de vigilancia periódica de la salud deben ceñirse al consentimiento del trabajador a realizárselos, puesto que son voluntarios, y específicos para los riesgos del puesto de trabajo. No es preciso recabar el consentimiento del trabajador cuando se trate de un caso excepcional de reconocimiento obligatorio (en adelante le llamaremos Vigilancia de la Salud Obligatoria (VSO) para simplificar), siempre y cuando haya un informe previo de los representantes de los trabajadores.

Figura 2. Protocolo de actuación ante un trabajador que se encuentra bajo los efectos de alcohol o drogas en el trabajo

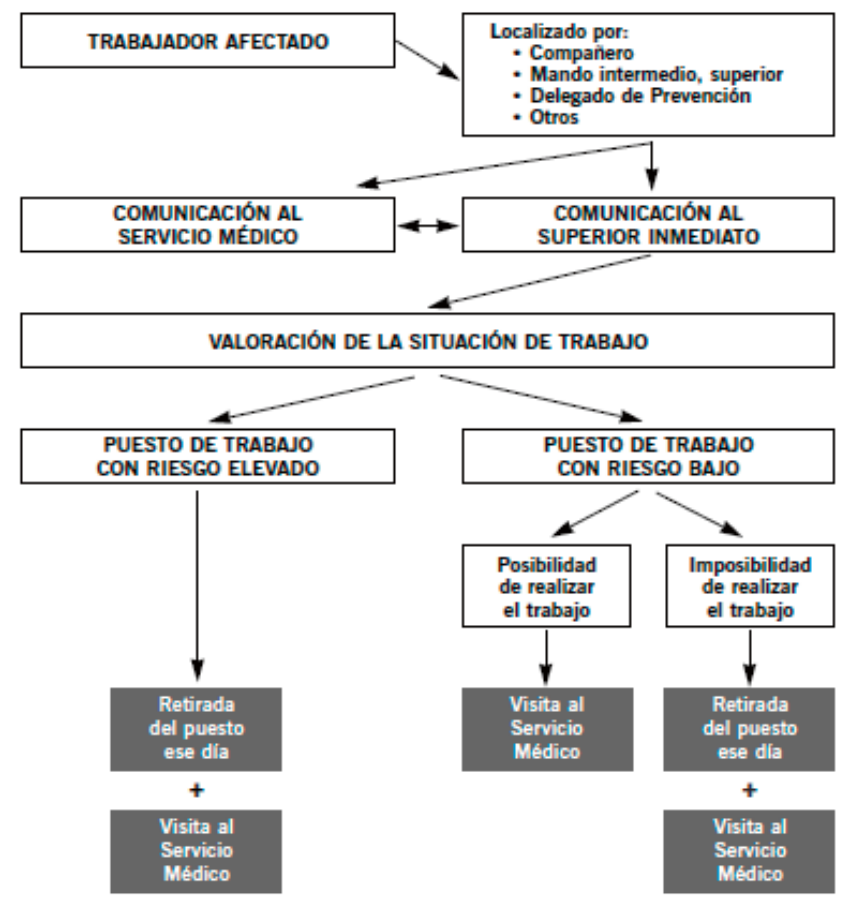

Fuente: Cómo prevenir los riesgos derivados del consumo indebido de alcohol y otras sustancias en el ámbito laboral. Confederación Empresarial Vasca (CONFEBASK). 2004.

El problema del trabajador adicto a drogas entrará en el ámbito de los riesgos laborales en el momento en que se considere (y se documente) que dicho trabajador puede representar un problema de seguridad, por ser un riesgo para sí mismo, para los demás trabajadores o para otras personas relacionadas con la empresa. No será preciso recabar su consentimiento, porque entra en el ámbito de la VSO. Según una 
sentencia del Tribunal Constitucional en un caso de despido improcedente por un resultado positivo a drogas en orina en una auxiliar administrativo de una empresa, "la obligatoriedad no puede imponerse, en cambio, si únicamente está en juego la salud del propio trabajador, sin el añadido de un riesgo o peligro cierto objetivable, pues aquél es libre para disponer de la vigilancia de su salud sometiéndose o no a los reconocimientos en atención a las circunstancias y valoraciones que estime pertinentes para la decisión" ${ }^{27}$.

Pero debe haber un informe previo de los representantes de los trabajadores. Solicitar un informe de cada caso particular puede ser poco operativo porque en situaciones de urgencia no se puede reunir a todos los representantes de los trabajadores, e incluso se entraría en conflictos de intimidad, dignidad y confidencialidad amplificando el número de personas conocedoras del problema, o bien se propone un "Protocolo de Vigilancia de la Salud Obligatoria" ${ }^{18}$ especificando las siguientes garantías:

1. Que el proceso se inicie con una solicitud de la Dirección de la empresa de "Aptitud por sospecha de riesgo importante para sí mismo o para terceros", aportando un informe escrito de sus responsables documentando que existe sospecha real de riesgo para la seguridad del trabajador o de terceras personas. La obligatoriedad sólo puede imponerse si existe un riesgo o un peligro cierto y objetivo sobre la salud.

2. Garantía de respeto a la intimidad y dignidad del trabajador. Determinadas pruebas (análisis de orina) que no requieren de una intervención sobre el cuerpo (intimidad corporal), pueden afectar a la intimidad de la persona en sentido amplio (pueden averiguarse datos relativos a la esfera íntima de la persona como el consumo de dogas). La actuación de la Empresa no vulnerará el derecho fundamental a la intimidad en función de que nos encontremos ante un supuesto excepcionado por la LPRL de obtener el consentimiento del trabajador para realizar el reconocimiento médico.

3. Garantía a la confidencialidad de los datos (los resultados de salud serán comunicados a los trabajadores afectados, y las conclusiones para el empresario o personas con responsabilidades en materia de prevención solo será en términos de "aptitud" y recomendaciones para el puesto).

4. Los datos relativos a la vigilancia de la salud de los trabajadores no podrán ser usados con fines discriminatorios ni en perjuicio del trabajador. Si con motivo de la aplicación del protocolo de VSO resultase un "no apto" para el puesto de trabajo, se intentaría, siempre que sea factible en la empresa, el Cambio de Puesto de Trabajo (CPT) a otro puesto en dónde no concurran las condiciones de riesgo.

En la Figura 3 se detalla un "Algoritmo de toma de decisiones en vigilancia de la salud obligatoria (VSO). Art. 22 LPRL", que puede ser de aplicación a los casos de trabajadores con alteraciones del comportamiento (documentados) que puedan representar un grave riesgo de seguridad para sí mismo o para terceros: trastornos de salud mental, trabajadores bajo los efectos del alcohol o drogas, etc. Todo el proceso debe estar adecuadamente documentado (Informes de solicitud de aptitud, Informes de derivación a especialistas en salud mental, en caso de precisar baja por incapacidad transitoria (IT/ITCC) se emite un informe al médico que gestione la baja: habitualmente su médico de Atención Primaria (MAP) o, en excepcionales ocasiones, de su mutua de accidentes de trabajo y enfermedad profesional (MATEPSS), Informes de alta del proceso de salud, Informes de la aptitud para el puesto de trabajo, etc...). La documentación generada durante todo el proceso se archiva en la Historia Clínico-laboral del trabajador, con todas las garantías posibles de seguridad de la documentación ${ }^{28,29}$. En caso de que el Médico del Trabajo emita un informe de "Apto con recomendaciones de adaptación del puesto", o "No Apto" y "Recomendación de Cambio de Puesto de Trabajo (CPT)", se planteará el seguimiento individualizado a realizar (revisión tras la adquisición de nuevas tareas o diferente puesto de trabajo). 
Figura 3. Algoritmo de toma de decisiones en Vigilancia de la Salud Obligatoria (VSO). Art.22 LPRL

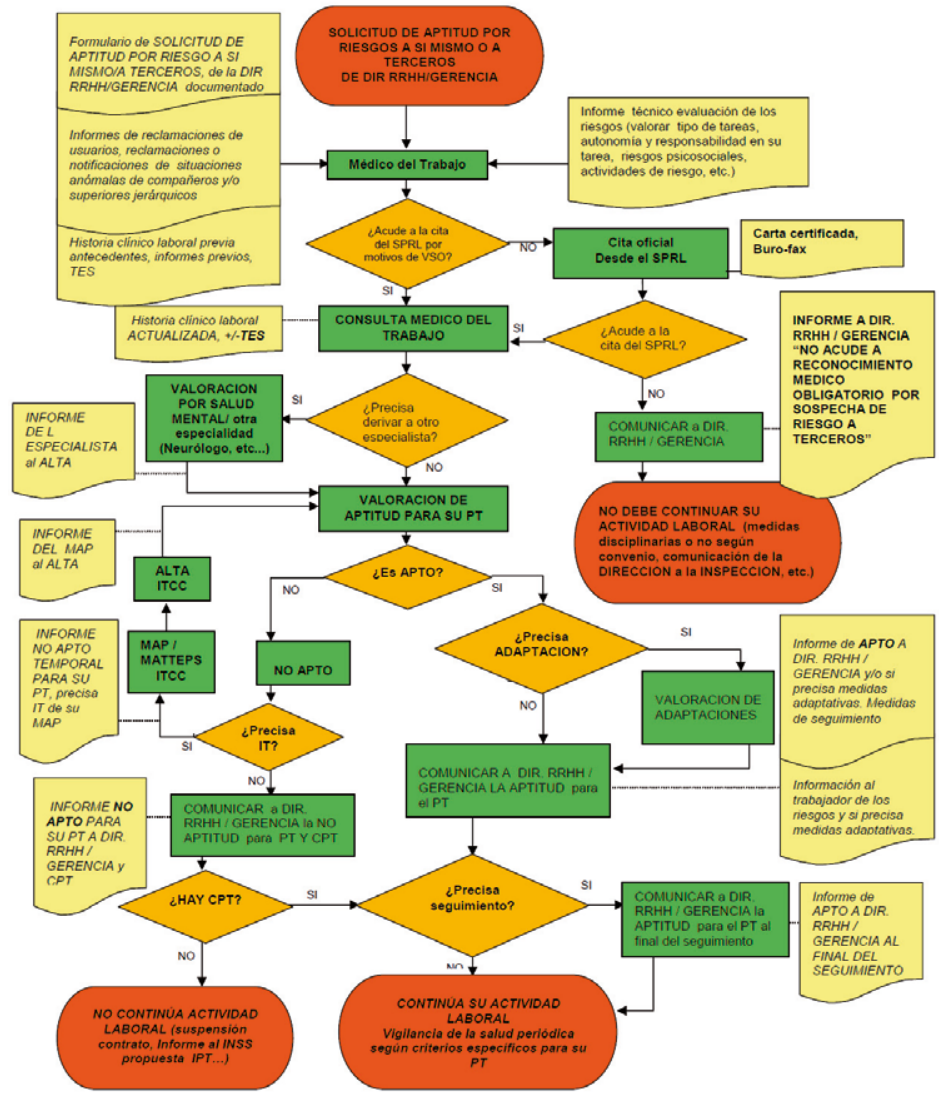

En el caso de trabajadores con problemas de adicción a drogas que provoquen conductas violentas o agresiones a compañeros en el medio laboral, se utilizaran las mismas estrategias de intervención que en las conductas agresivas fuera del marco de la intoxicación. Son situaciones de urgencia, que precisan de la intervención de una persona de la empresa con autoridad y con formación adecuada para poder controlar dichas situaciones: aplicando técnicas de desactivación o desescalada. Intervendrá verbalmente intentando reducir la tensión, dirigiéndose al trabajador violento de forma tranquila y no provocadora, intentando establecer una conversación y planteándole otras alternativas y ayuda médica, si fuese necesario ${ }^{5,30}$. En situaciones extremas, puede ser necesaria una intervención contra la voluntad del trabajador, con empleo de contención física, sujeción mecánica e intervención farmacológica si existe riesgo para el trabajador o para otros (atención de la urgencia en el servicio médico de la empresa o aviso a los Servicios especiales de urgencias). Conviene recordar, para estas situaciones, que el ingreso psiquiátrico involuntario se puede solicitar en aplicación del Art. 763 de la Ley de Enjuiciamiento Civil LEC (Ley 1/2000) ${ }^{30,31}$. Según el referido artículo, el internamiento involuntario de una persona que no esté en condiciones de decidirlo por sí misma, a causa de un trastorno psíquico, debe cumplir los siguientes requisitos:

1. Que se precisa autorización judicial previa, en las situaciones no urgentes, o bien

2. Qué en situaciones de urgencia, es suficiente la indicación por un facultativo, y la subsiguiente comunicación al Juzgado competente en el plazo máximo de 24 horas. La LEC marca un plazo máximo de 72 horas para que el Juez competente examine al paciente ingresado por vía de urgencia y emita la correspondiente decisión de autorizar o no dicho internamiento.

El Art. 763 de la LEC reconoce explícitamente el derecho de los pacientes a estar representados legalmente durante todo el procedimiento que supone el internamiento involuntario, y recoge, también explícitamente, que la decisión del alta de estos pacientes 
corresponde a los facultativos encargados de su tratamiento, con la obligación de comunicarlo al Juzgado competente.

Además de poder requerirse la actuación del Médico del Trabajo ante situaciones urgentes, y solicitud de "valoración de aptitud por procedimiento de vigilancia de la salud obligatoria”, el especialista en Medicina del Trabajo deberá realizar otras actividades de salud laboral, aplicadas al problema de las drogodependencias en el lugar de trabajo. El Médico del Trabajo, en el desarrollo de sus competencias ${ }^{32}$, deberá desarrollar su actividad para prevenir la enfermedad y sus consecuencias:

1. En el marco de la Prevención Primaria: detectando factores de riesgo y actuando sobre los mismos: tanto factores de riesgo colectivos en la organización y en el puesto de trabajo (Evaluación de riesgos psicosociales y de puestos de trabajo de fácil acceso a psicofármacos, Programas de formación, etc.) como factores individuales personales (Vigilancia de la salud individual y detección precoz de trabajadores especialmente sensibles (TES), según Art. 25 LPRL $^{3}$.

2. En el marco de la Prevención Secundaria: realizando el diagnóstico precoz en los trabajadores consumidores y/o adictos a sustancias y la inmediata derivación al SNS para tratamiento de desintoxicación y deshabituación.

3. Y por último, en el marco de la Prevención Terciaria, facilitando la rehabilitación laboral y la reincorporación laboral del trabajador tras tratamiento de deshabituación, con garantías de seguridad.

A continuación se desarrollan las actuaciones del Médico del Trabajo en el amplio campo de la prevención laboral, aplicado al problema de las drogodependencias que afectan a los trabajadores.

\section{Prevención primaria: evitar los factores de riesgo}

Según la OMS, las medidas de Prevención Primaria de la enfermedad son un conjunto de actividades sanitarias que se realizan tanto por la comunidad o los gobiernos como por el personal sanitario antes de que aparezca una determinada enfermedad.

En materia de Prevención de Riesgos Laborales (PRL), una de las herramientas básicas de prevención es la Evaluación de Riesgos Laborales (ERL). Es un proceso dirigido a estimar la magnitud de aquellos riesgos que no hayan podido evitarse, obteniendo la información necesaria para que el empresario pueda tomar una decisión adecuada sobre la necesidad de adoptar medidas preventivas y, en ese caso, del tipo de medidas a adoptar (Art.3 RD 39/1997, de 17 de enero, por el que se aprueba el Reglamento del Servicio de Prevención de Riesgos Laborales RSPRL) ${ }^{32}$. Su objetivo es realizar un diagnóstico de la situación de trabajo y elaborar un programa de mejora para reducir, y si es posible, eliminar los riesgos detectados (Art. 15 LPRL) ${ }^{3}$. No se puede utilizar cualquier método para la evaluación de los riesgos laborales, ya que la norma es muy clara: el método de evaluación debe ser un procedimiento o instrumento válido de medida y valoración, que permita obtener información y llevar a cabo el análisis de las condiciones de trabajo en que, efectivamente, se realiza dicho trabajo.

Los riesgos psicosociales, siguiendo la definición que da el Instituto Nacional de Seguridad e Higiene en el Trabajo (INSHT), son aquellas condiciones presentes en una situación laboral directamente relacionadas con las condiciones ambientales (agentes físicos, químicos y biológicos), con la organización, con los procedimientos y métodos de trabajo, con las relaciones entre los trabajadores, con el contenido del trabajo y con la realización de las tareas, y que pueden afectar a través de mecanismos psicológicos y fisiológicos, tanto a la salud del trabajador como al desempeño de su labor ${ }^{33}$. Se pueden y se deben evaluar, pero no es sencillo, por su complejidad: son numerosos, de diversa naturaleza y, además, son condiciones mantenidas en el tiempo y, a veces, los efectos se manifiestan mucho tiempo después. Además, en su percepción, también intervienen las variables personales del trabajador: las actitudes, las capacidades, la motivación, las experiencias y formación previa y los recursos personales (técnicas de afrontamiento del 
estrés, etc.). A grandes rasgos, se puede decir que los riesgos psicosociales son las condiciones del trabajo, y sobre todo de su organización, nocivas para la salud.

La Evaluación de Riesgos Psicosociales (ERP) es un proceso dirigido a estimar la magnitud de aquellos riesgos psicosociales que no hayan podido evitarse, obteniendo la información necesaria para que el empresario pueda tomar una decisión adecuada sobre la necesidad de adoptar medidas preventivas, y del tipo de medidas a adoptar (Planificación de las medidas preventivas frente a los riesgos psicosociales). ¿Qué método se puede utilizar para realizar una Evaluación de Riesgos Psicosociales? Se debe tener en cuenta que el procedimiento de ERP deberá proporcionar confianza sobre su resultado (Art. 15 LPRL) ${ }^{3}$, y debe cumplir estándares de calidad científica, metodológicos y profesionales (válido y fiable) ${ }^{34,35}$. Además, para la selección del método, se deben contemplar tanto el alcance de la evaluación (método específico para valorar factores de riesgo psicosocial, no para evaluar consecuencias de los mismos, como son los síntomas de estrés), como las características de la empresa a la que va a ir dirigido (tipo de actividad, turnicidad, etc.). En la Tabla VI se propone una clasificación de métodos que históricamente se han utilizado en prevención y en salud laboral (Test de ansiedad, etc.), pero solo algunos son específicos para la ERP ${ }^{34,35}$.

En el proceso de ERP, la intervención del Médico del Trabajo es de asesoramiento en el proceso de selección del método (ya que "conoce" la salud laboral de los trabajadores por los resultados de los reconocimientos médicos: sabe que sectores tienen un mayor número de trabajadores con ansiedad o somatizaciones, dónde se han producido situaciones de conflicto entre trabajadores o con usuarios del servicio que ofrece la empresa, o problemas previos que han precisado ya una intervención personalizada, etc.) ${ }^{33,35}$. La ERP es un procedimiento técnico, pero la Prevención de Riesgos Laborales debe ser interdisciplinar. Una vez se ha estimado la magnitud del riesgo, de nuevo el Médico del Trabajo debe intervenir en la Planificación de la acción preventiva, proponiendo acciones de mejora desde la Salud Laboral ${ }^{36}$.

\section{Tabla VI. Clases de Métodos de Evaluación de Riesgos Psicosociales}

M. Globales de ERL

M. Generales de evaluación de condiciones ergonómicas (incluye R. Psicosocial)

M. Generales de evaluación de Riesgos Psicosociales

M. Especificos para evaluar un factor o área Psicosocial o sus consecuencias (efectos)

M. Especificos por area de actividad para evaluar los riesgos Psicosociales de dicha actividad
Su objetivo es la evaluación global de las condiciones de trabajo e incluyen algún módulo referente a $\mathrm{F}$. Psicosociales. Ej.: PVCHECK, etc. Muy incompleto para ERP.

Su objetivo es la evaluación específica de riesgos ergonómicos en la que se incluyan los R. Psicosociales. Ej.: LEST, Perfil de Puesto s, ANACT, etc. Muy incompleto para ERP.

Su objetivo es la ERP. Se dirigen a toda la población (si es muy extensa, muestra representativa) que se desea estudiar, para detectar R. Ps icosociales que pueden incidir en la salud, pero no pretenden evaluar consecuencias concretas (p. ej. mobbing). Ej.: FPSICO deIINSHT. ISTAS21.

Pretenden evaluar las consecuencias sobre la salud derivadas de la exposición a riesgos. Ej.: m. de evaluación de estrés (VBBA, IRE-32. NIOSH Generis Job Stress Ouestionnaire, JCa, wocca, etc, de Burnout (MBI, Staff Burnout Escale, etc), de Mobbing (Leymann Inventory of Psychological Terrorizalion), etc. Muy concretos.

Su objetivo es realizar una Evaluación de Riesgos Psicosociales a un determinado sector laboral. Ej.: INERMAP (método del Instituto Mapfre Ergonomía), SANIMAP en sector sanitario.

Tomado de: Antes y después de la evaluación de riesgos psicosociales en el ámbito sanitario ${ }^{33}$

Sin embargo, no sólo los riesgos psicosociales se han relacionado con la facilitación para el consumo de drogas de algunos trabajadores, la accesibilidad a drogas y sustancias psicoactivas en determinados puestos de trabajo es un factor de riesgo 
muy importante (tabla VII) ${ }^{13}$. Siempre se debe tener en cuenta en la ERL la fácil accesibilidad a las drogas, en algunos sectores muy específicos: hostelería (personal de discotecas, salas de fiesta y lugares de ocio, etc.), profesiones sanitarias (anestesistas y consumo de opiáceos, consumo de psicofármacos en personal de enfermería y urgencias, etc. $)^{11,18}$, Centros veterinarios y personal de Centros Penitenciarios ${ }^{24}$, entre otros. Por establecer un símil, un adicto a opiáceos trabajando en un servicio de anestesia, sería como un niño en una "tienda de golosinas" ${ }^{37}$. Se debe actuar sobre el riesgo, dificultando el acceso fácil (por ejemplo, con un control exhaustivo de opiáceos y psicofármacos en el medio sanitario, vigilando si los pacientes han recibido dosis completas por su tolerancia al dolor en las salas de reanimación, etc.).

Tabla VII. Factores de riesgo que propician o facilitan en consumo de drogas por parte de los trabajadores
Relacionados con la organización del proceso productivo
1. Jornadas de trabajo demasiado prolongadas
2. Rotación horaria
3. Ritmos de trabajo demasiado intensos (estrés laboral)
4. Sobre carga de trabajo
5. Escasas posibilidades para la promoción profesional

Relacionados con el puesto de trabajo y la tarea

1. Trabajos repetitivos y escasamente motivadores

2. Condiciones climatológicas adversas

3. Contaminación y toxicidad ambiental

4. Trabajos aislados sin contacto con compañeros o superiores

5. Traslados frecuentes de puesto de trabajo

6. Puestos de trabajo asociados a una mayor proximidad o disponibilidad de sustancias

7. Cultura del puesto y/o profesión

Relacionados con el ambiente laboral

1. Conflictividad laboral

2. Inestabilidad laboral

3. Ambiente de gran competitividad

4. Presencia de consumidores en el centro de trabajo

5. Presión de los compañeros de trabajo

6. Tolerancia en el centro de trabajo hacia los consumos de ciertas drogas

7. Accesibilidad a determinadas sustancias

Tomado de: Guía para la Mejora de la Gestión Preventiva . Drogodependencias en el medio laboral ${ }^{13}$.

En el caso del personal sanitario, y más concretamente en los servicios de reanimación, se ha propuesto la teoría del riesgo higiénico ocupacional: concentraciones de opiáceos en ambiente. Algunos autores defienden un nuevo factor de riesgo asociado al consumo de opiáceos como sustancias de abuso entre los anestesistas: la exposición ambiental a aerosoles de opiáceos. Su hipótesis se avala midiendo en aire las concentraciones de opiáceos intravenosos (propofol y fentanilo) que se utilizan en pacientes, y que se aerosolizan en el ambiente. Se concluye que los anestesistas están expuestos, durante sus horas de trabajo, a altas concentraciones ambientales ${ }^{18,38,39}$. Este supuesto del riesgo higiénico por concentraciones ambientales de droga también debería contemplarse en algunos locales de ocio (discotecas, etc.), en donde es fácil que puedan existir concentraciones ambientales de polvo de cocaína, y otras sustancias, en suspensión, y al que el personal laboral se vería expuesto.

En realidad, habría que plantearse no sólo en qué medida el ambiente laboral puede condicionar la adicción de algunos trabajadores expuestos, sino, también, si los adictos a determinadas drogas eligen los puestos de trabajo dónde el acceso a la droga es más sencillo. En este sentido, algunos autores han observado que la mayoría de los médicos residentes de Anestesia en programas de deshabituación confirmaron haber elegido la especialidad por el fácil acceso a sustancias psicoactivas. De hecho, un 33.7\% del total de médicos de programas de terapia de adicciones eran residentes de anestesia, presentando una incidencia 7.4 veces mayor que la presentada por los residentes de otras 
especialidades $^{40}$. En una encuesta de la ASA (American Society of Anesthesiologists) los residentes presentaron una prevalencia de un 34,5\% de consumo de sustancias de abuso, con predilección por opioides como fentanilo y sufentanilo ${ }^{37}$.

Determinar la susceptibilidad personal de los trabajadores al posible consumo de drogas, identificando factores de riesgo individual (detección de trabajadores especialmente sensibles (TES), según Art. $25 \mathrm{LPRL}^{3}$ ), es misión exclusiva del Médico del Trabajo, en la actividad de vigilancia de la salud individual. Serían TES aquellos con mala respuesta al estrés (cuadros de ansiedad importantes, severas somatizaciones, etc.), con antecedentes personales de trastornos psicológicos, o de conductas adictivas previas, con historia familiar de adicciones, o con alto riesgo socio-familiar (divorcios traumáticos, presión social, etc.).

Para la valoración del riesgo individual es fundamental realizar una exhaustiva historia clínico laboral, valorando (Art.37 RSPRL) ${ }^{32}$ :

1. Antecedentes:

a. Antecedentes laborales (Anamnesis laboral): trabajos previos, "trabajos de riesgo" para el consumo de alcohol o drogas y descripción del puesto actual

b. Antecedentes familiares: riesgo genético por conductas de adicción en padres. Cargas o problemas familiares importantes, entorno socio-familiar.

c. Antecedentes personales: ansiedad y mala respuesta adaptativa al estrés, somatizaciones, trastornos psicológicos (cuadros depresivos previos, trastornos desadaptativos, trastornos de personalidad, patrones de baja autoestima) o de conductas adictivas previas.

2. Historia actual:

a. Características del Puesto de trabajo actual: además de la descripción del puesto (horario, turnos, tareas), y de los protocolos que sean de aplicación según los datos de la Evaluación de Riesgos (ERL), también habría que contar con la descripción del riesgo psicosocial del puesto de trabajo así como la complejidad de la tarea. En situaciones comprometidas, dónde la descripción del propio trabajador no se corresponde con lo objetivizado en el informe de evaluación para el puesto, es recomendable realizar entrevistas semiestructuradas de escucha activa, no sólo al propio trabajador, sino también a compañeros, subordinados y/o superiores, para clarificar la presencia o no de un determinado riesgo psicosocial, en el puesto de trabajo.

b. Anamnesis general (por órganos y aparatos) y, más específica, de la esfera psicológica. Síntomas actuales: tristeza, ansiedad, angustia, etc. Especificar hábitos (consumo de tabaco, alcohol, sustancias de abuso, bebidas excitantes) y consumo de medicamentos.

3. Exploración general: valoración del aspecto general (valoración de signos que pudieran estar asociados al consumo previo de drogas, como determinados tatuajes en la piel, lesiones venosas, higiene descuidada y deterioro físico, etc.), exploración física general (según otros protocolos de aplicación) y, más específicamente, exploración neurológica (reflejos, equilibrio, coordinación),

4. Pruebas complementarias: su indicación depende de los protocolos de Vigilancia Sanitaria Específicos que sean de aplicación por su puesto de trabajo (analítica (Bioquímica, hemograma, puede precisar serologías para valorar el riesgo biológico y/o vacunaciones), EKG, espirometría, etc.). Según los datos recogidos en la anamnesis, se podrían realizar test o cuestionarios específicos (test de ansiedad de Goldberg, CAGE, etc.), pero sólo se podrían realizar controles de drogas contando con el consentimiento informado del trabajador, y con objeto de iniciar tratamiento (salvo que este protocolizado el riesgo, en exámenes de salud obligatorios, según los supuestos del Art. 22 LPRL, como se verá más adelante). 
En el caso de detectar situaciones de riesgo y Trabajadores especialmente sensibles (para el riesgo de altas demandas de estrés), se podrán proponer adaptaciones del puesto e intervenciones sobre el trabajador en riesgo (seguimiento periódico y frecuente, información sobre los riesgos a los que está expuesto y dotarle de estrategias de afrontamiento cuyos objetivos sean un incremento de autoestima, responsabilidad en toma de decisiones, reducción de ansiedad, autoconfianza, mejora de relaciones interpersonales, incrementar la resistencia frente a la presión e influencia de grupo para el consumo de drogas, etc.). En ocasiones son de ayuda las intervenciones con técnicas cognitivo conductuales, orientándole sobre ayuda profesional al respecto. Se debe buscar ayuda en los programas de la red asistencial pública, programas de ayuntamientos y comunidades autónomas, etc., para ofrecer información individualizada a los trabajadores.

El Médico del Trabajo también puede y debe participar de forma directa y activa en los programas de formación e información a los trabajadores en materia de drogodependencias.

1. Campañas de sensibilización e Información a los trabajadores ${ }^{13}$ : Se realizan como estrategias preventivas de difusión de información a través de folletos, trípticos, carteles, visualización de videos, charlas, conferencias y seminarios informativos. Su objetivo primordial es evitar el consumo de drogas entre los trabajadores. Se pretende conseguir a través de otros objetivos secundarios, como son:

a. Crear una opinión objetiva acerca del consumo de drogas y de su incidencia en los distintos ámbitos profesionales y sociales.

b. Incrementar conocimientos sobre drogas, sus consecuencias y su uso.

c. Promover hábitos de salud alternativos al consumo de drogas. Informar de los diferentes recursos que la empresa y las instituciones públicas y privadas disponen para atender a personas con problemas.

2. Programas de Formación en materia de drogodependencias y educación para la salud ${ }^{13}$ : Son otro tipo de estrategias preventivas que se pueden llevar a cabo a través de seminarios dirigidos a la totalidad de los trabajadores, o creación de talleres y grupos de discusión. Su objetivo es doble:

a. Intensificar las acciones formativas, garantizando un conocimiento a los agentes sociales representados en la empresa, los cuales son susceptibles de actuar como mediadores sociales.

b. Garantizar un nivel alto de especialización en el campo de las drogodependencias a los técnicos de prevención.

Según la OMS, uno de los instrumentos de la promoción de la salud y de la acción preventiva es la educación para la salud, que aborda además de la transmisión de la información, el fomento de la motivación, las habilidades personales y la autoestima, necesarias para adoptar medidas destinadas a mejorar la salud. Las estrategias preventivas de formación e información a los trabajadores en materia de drogodependencias deben llevarse a cabo por un equipo interdisciplinar en el que deben intervenir los miembros del Servicio de Prevención de Riesgos Laborales, los representantes de los trabajadores con competencias en Prevención de Riesgos Laborales (Delegados de Prevención) y la Organización de la empresa. Son medidas encaminadas a la reducción de la demanda (Prevención Primaria), evitando los riesgos en su origen.

\section{Prevención secundaria: diagnóstico precoz}

También se denomina diagnóstico precoz, cribado, o screening (OMS). Un programa de detección precoz es un programa epidemiológico de aplicación sistemática o universal, para detectar en una población determinada y asintomática, una enfermedad grave en estadio inicial o precoz, con el objetivo de disminuir la tasa de mortalidad y puede estar asociada a un tratamiento eficaz o curativo. La prevención secundaria se basa en los 
cribados poblacionales y para aplicar estos han de darse unas condiciones predeterminadas definidas por Frame y Carslon para justificar el screening de una patología.

- Que la enfermedad represente un problema de salud importante con un marcado efecto en la calidad y duración del tiempo de vida.

- Que la enfermedad tenga una etapa inicial asintomática prolongada y se conozca su historia natural.

- Que se disponga de un tratamiento eficaz y aceptado por la población en caso de encontrar la enfermedad en estadio inicial.

- Que se disponga de una prueba de cribado rápida, segura, fácil de realizar, con alta sensibilidad, especificidad, alto valor predictivo positivo, y bien aceptada por médicos y pacientes.

- Que la prueba de cribado tenga una buena relación coste-efectividad. Que la detección precoz de la enfermedad y su tratamiento en el periodo asintomático disminuya la morbilidad y mortalidad global o cada una de ellas por separado.

En el caso de las drogodependencias en el ámbito laboral, aunque se sospeche una alta prevalencia del consumo de drogas entre los trabajadores de la empresa, no es ético realizar un programa de screening a todos los trabajadores, porque son pruebas que vulneran el derecho fundamental a la intimidad del trabajador y no se ciñen a las competencias de los reconocimientos de la vigilancia de la salud (Art.22 LPRL) ${ }^{3}$. Las pruebas de drogas en orina o saliva, aunque no requieran de una intervención sobre el cuerpo (intimidad corporal), pueden afectar a la intimidad de la persona en sentido amplio (pueden averiguarse datos relativos a la esfera íntima de la persona como el consumo de dogas). Si por parte de la empresa se desea establecer y difundir una Política de Prevención de Drogas en el lugar de trabajo, pactada con los representantes de los trabajadores, se planificará el Programa de Prevención y el Protocolo de actuación en el seno del Comité de Empresa y Comité de Seguridad y salud. Debe estar consensuado entre la empresa y los representantes de los trabajadores, y estará integrado en la Política de la Salud Laboral, estableciendo garantías para los trabajadores ${ }^{22-24}$.

Un supuesto diferente es la realización de pruebas de detección de drogas en los reconocimientos médicos específicos de vigilancia de la salud, contempladas en los protocolos de vigilancia de la salud específicos a determinados riesgos evaluados (ERL). Se deben atener a los supuestos del Art. 22 de la LPRL ${ }^{3}$. No se deben realizar a todos los trabajadores, sea cual sea su puesto de trabajo, sino únicamente a aquellos en los que esté protocolizado en su puesto de trabajo por riesgo importante a terceros, además de a sí mismos (P. ej.: pilotos de aviones, conductores de metro, etc.). En estos casos, la actuación de la Empresa no vulnerará el derecho fundamental a la intimidad, ya que nos encontramos ante un supuesto excepcionado por la LPRL de obtener el consentimiento del trabajador para realizar el reconocimiento médico.

Los tipos de reconocimientos médicos, o exámenes de vigilancia de la salud, que marca la norma (Art. 37, RSPRL) ${ }^{32}$, en las condiciones fijadas por el Art. 22 LPRL, son los siguientes:

1. ${ }^{\circ}$ Una evaluación de la salud de los trabajadores inicial después de la incorporación al trabajo o después de la asignación de tareas específicas con nuevos riesgos para la salud.

2. ${ }^{\circ}$ Una evaluación de la salud de los trabajadores que reanuden el trabajo tras una ausencia prolongada por motivos de salud, con la finalidad de descubrir sus eventuales orígenes profesionales y recomendar una acción apropiada para proteger a los trabajadores.

$3 .^{\circ}$ Una vigilancia de la salud a intervalos periódicos.

La vigilancia de la salud estará sometida a protocolos específicos u otros medios existentes con respecto a los factores de riesgo a los que esté expuesto el 
trabajador $[\ldots]^{32}$. El contenido de los exámenes de vigilancia de la salud también se especifica en la norma ${ }^{32}$ : "Los exámenes de salud incluirán, en todo caso, una historia clínico-laboral, en la que además de los datos de anamnesis, exploración clínica y control biológico y estudios complementarios en función de los riesgos inherentes al trabajo, se hará constar una descripción detallada del puesto de trabajo, el tiempo de permanencia en el mismo, los riesgos detectados en el análisis de las condiciones de trabajo, y las medidas de prevención adoptadas". En esencia, es el mismo contenido que ya se ha descrito, a título orientativo, en la Historia Clínico-laboral en los Trabajadores Especialmente sensibles (TES).

En definitiva, no se pueden realizar pruebas (control biológico, CDLT) fuera del contexto que marca la norma para los exámenes de la vigilancia de la salud (protocolos específicos según los riesgos detectados). En caso de contemplarse, como pruebas complementarias del examen de salud, la realización de controles de drogas en el lugar de trabajo (CDLT) ${ }^{4,18}$ deben ceñirse estrictamente a procedimientos de calidad que garanticen la fiabilidad del proceso, en cuanto a la selección del método más adecuado (selección de muestra mas adecuada: orina, saliva, o pelo para valorar el consumo en el tiempo, no son útiles las muestras de sangre salvo para consumos de las 2 horas previas), metodología de la toma de muestra (evitar manipulaciones de la misma), la custodia, conservación y transporte de la misma, el laboratorio de referencia, el método elegido (sensible y especifico, la primera prueba se realizará con técnica de inmunoanálisis, utilizando cromatografía de gases como prueba confirmatoria) y la posibilidad, siempre, de realizar una contraprueba (hay que ser extremadamente cuidadoso, por la posibilidad de resultados "falsos positivos"). Podemos resumir los requisitos ${ }^{4,18}$ de los CDLT en los siguientes puntos:

1. Las pruebas deben ser fiables. Las técnicas de inmunoanálisis sólo serían pruebas de screening, por las implicaciones legales, se deben realizar pruebas confirmatorias (la Cromatografía de Gases conjuntamente con la espectrofotometría de masas (GC-MS) se considera la prueba más fiable en la actualidad) ${ }^{41,42}$.

2. El laboratorio debe tener amplia experiencia acreditada en el campo del análisis de drogas y garantizar la custodia de las muestras durante tiempo suficiente como para poder solicitar un contraanálisis, si se considera necesario.

3. La elección de la muestra debe ser la adecuada a la indicación del CDLT. La orina es el fluido biológico preferido para el análisis de drogas ilegales y sus metabolitos, siempre que se garantice la autenticidad de la muestra para evitar los "falsos negativos" por su adulteración ${ }^{18,41}$. La recogida de muestras de sangre sólo estaría indicado para la detección de drogas en las urgencias clínicas, ya que las sustancias psicoactivas tienen una vida media muy corta en sangre ( 1 hora aproximadamente para la cocaína $)^{18}$. Las muestras de sangre no estarían indicadas para los CDLT. Las muestras de pelo, que parecían evitar el problema de la falsificación, se pueden indicar para demostrar un consumo a largo plazo. Este tipo de muestra habría que interpretarlo con cautela: es posible "el falso negativo" por su adulteración con peróxidos (presentes en algunos tintes capilares), la concentración de drogas fijadas en cabellos oscuros es mucho mayor que en cabellos claros, se precisa experiencia y adiestramiento para realizar la toma de muestra (Tabla VIII), se invade la privacidad del individuo al dejar una pequeña "calva" en el vértex, algunos tipos de sustancias (p.ej. las drogas ácidas) son muy difíciles de detectar y también es posible el riesgo de falsos positivos exógenos (contaminación de la cara externa del pelo por las concentraciones de drogas ambientales) ${ }^{38,41}$. Pero las pruebas de drogas en pelo pueden ser un complemento a otros procedimientos de despistaje de consumo de drogas o para establecer una historia de consumo de droga a lo lago del tiempo.

4. Se debe tener recogido en un documento un protocolo de actuación en cuanto a la recogida, custodia y envío de muestra, que sea específico del servicio de salud de la empresa y que sea riguroso ${ }^{18}$. 
Los informes del Médico del Trabajo siempre se emitirán en términos de "aptitud para el puesto", aunque el trabajador tiene derecho a conocer los resultados de su salud (y a solicitar una contraprueba de un positivo en una analítica de detección de drogas). En caso de realizar el diagnóstico de trabajadores consumidores y/o adictos a sustancias, además de valorar la aptitud para el puesto de trabajo (ver Figura 3, con algoritmo de actuación del Médico del Trabajo en Vigilancia de la salud Obligatoria), se le debe ofrecer la inmediata derivación al SNS para tratamiento de desintoxicación y deshabituación.

Tabla VIII. Pasos generales de recogida de muestra de pelo para análisis Toxicológico

Zona de recogida de muestra:

- VERTEX (región posterior de la cabeza). Un $85 \%$ de esta área presenta pelo en fase de crecimiento activo, y, por tanto, se podría fijar en ella mayor cantidad de droga.

Lugar de recogida de muestra:

- En las dependencias del Servicio Médico. Siempre deben obtenerse las muestras en un ambiente no contaminado por la droga.

Procedimiento:

- CORTAR (no arrancar) el cabello al rás (lo más próximo posible al cuero cabelludo, pero sin raíz.

Cantidad de Mue stra :

- 100 a $200 \mathrm{mg}$. de pelo (mechón de diámetro similar al de un lápiz o grosor de un dedo delgado)

- Es la cantidad de muestra suficiente para permitir estudios de screening y de confirmación (GC-MS). Se debe custodiar muestra durante un periodo de tiempo.

Longitud mlnima:

- Mechón de al menos de $1 \mathrm{~cm}$ de largo.

Preparación de la muestra para envío:

- Pegar con cinta adhesiva el mechón de pelo en un folio de papel por sus dos extremos, indicando con una anotación cuál es la parte proximal (cercana a la raíz) y cuál es la distal (punta). La muestra no debe estar húmeda, secarla primero.

- Introducir en un sobre de papel. junto con el volante peticionario adecuadamente cumplimentado (identificación, tipo de muestra, análisis solicitado, etc.)

- Las muestras de pelo pueden ser conservadas a temperatura ambiente, no necesitan nevera.

Tomado de: PerKins de Piacentino (2005)

\section{Prevención terciaria: reincorporación laboral}

Las medidas de Prevención Terciaria son aquellas que buscan el restablecimiento de la salud una vez que ha aparecido la enfermedad. El restablecimiento de la salud se realiza tanto en atención primaria como en atención especializada (Centros de Salud Mental). Una vez restablecida la salud, se debe facilitar la reincorporación laboral, para lo cual resulta imprescindible la coordinación del Médico del Trabajo con los profesionales de la red asistencial. Se consigue la mutua colaboración informando adecuadamente del objetivo de la coordinación de recursos (lo ideal sería establecer líneas oficiales de comunicación, con la garantía de no agresión de los derechos del trabajador -para el Médico del Trabajo- y, a su vez, paciente -para los profesionales de la red sanitaria asistencial-).

Si se realiza una evaluación de la salud de un trabajador que reanude el trabajo tras una ausencia prolongada por motivos de salud (tratamiento de deshabituación), se le considerará TES frente a determinados riesgos (riesgo de estrés (turnos cambiantes, etc.), otros riesgos) durante un periodo que se considere adecuado para el seguimiento por el médico del Trabajo. Se debe considerar la recomendación de reincorporación laboral progresiva, a tareas de responsabilidad hacia sí mismo o terceros (adaptación de su puesto de trabajo en caso de manejo de maquinaria peligrosa, o personal sanitario con riesgo directo hacia terceras personas) ${ }^{18}$ y el periodo de seguimiento personalizado. 


\section{Reincorporación laboral y procedimiento de seguimiento}

El seguimiento, para que sea efectivo, debe estar perfectamente protocolizado, informar de las pautas de seguimiento al trabajador antes de dar inicio al mismo y conseguir su compromiso o aceptación, siendo siempre especifico para cada caso (diferentes riesgos, diferentes situaciones). El seguimiento es un proceso que consume muchos recursos: requiere muchísima implicación del personal sanitario del SPRL, gastos de analíticas y laboratorio, gastos de transporte de muestras, etc. Y sólo si el trabajador entiende que es en su beneficio, servirá para su rehabilitación personal y laboral.

En casos muy concretos, puede ser beneficioso establecer un contrato terapéutico (es útil en caso de cirujanos, personal de quirófano, etc.) en dónde se especifiquen las condiciones del seguimiento ${ }^{18}$. Se incorpora un modelo aplicado a personal sanitario (Figura 4). El contenido mínimo que debe contemplar, se resume en los siguientes $\operatorname{apartados}^{18}$ :

- Datos de Identidad del trabajador en seguimiento.

- Identidad del responsable (facultativo, psicoterapeuta) del tratamiento de deshabituación y/o psicoterapia.

- Arbitraje del SPRL para realizar controles en el lugar de trabajo y emitir Aptitud laboral.

- Se le facilita una "falsa identidad" para preservar la intimidad (confidencialidad al realizar el envío de muestras al laboratorio, etc.).

- Tipo de controles toxicológicos que se van a realizar.

- Adaptación progresiva a la normalidad laboral y condiciones (asumir tareas de más complejidad y responsabilidad progresivamente). Duración del proceso.

- Condiciones en caso de "positivos" en los controles analíticos.

- Posibilidad de negativa al seguimiento, y consecuencias derivadas de dicha negativa.

- Fecha y firmas (del trabajador causante del contrato terapéutico y del Responsable de la Dirección y/o Responsable del SPRL, dependiendo de cómo se haya planteado).

De igual modo, se debe diseñar un Protocolo de Controles Toxicológicos personalizado $^{18}$, especificando el tipo de muestra/s que se van a seleccionar, la indicación de pruebas, las condiciones de recogida de muestra, las condiciones de conservación y envío de dichas muestras al laboratorio de referencia, custodia de muestras y documentos de consentimiento para realizar la toma de muestras así como de información recibida por el trabajador (Figura 5).

En los programas de seguimiento, se ha demostrado que la programación del análisis de orina, 3 días por semana, es la más eficaz para la detección del uso de heroína o cocaína, sin embargo genera un alto coste y sólo se recomienda en circunstancias excepcionales. Los test a intervalos aleatorios intermitentes pueden ser los que tengan mejor coste-eficacia ${ }^{18,41}$. 
Figura 4. Reincorporación laboral y procedimiento de seguimiento. Modelo de contrato terapéutico

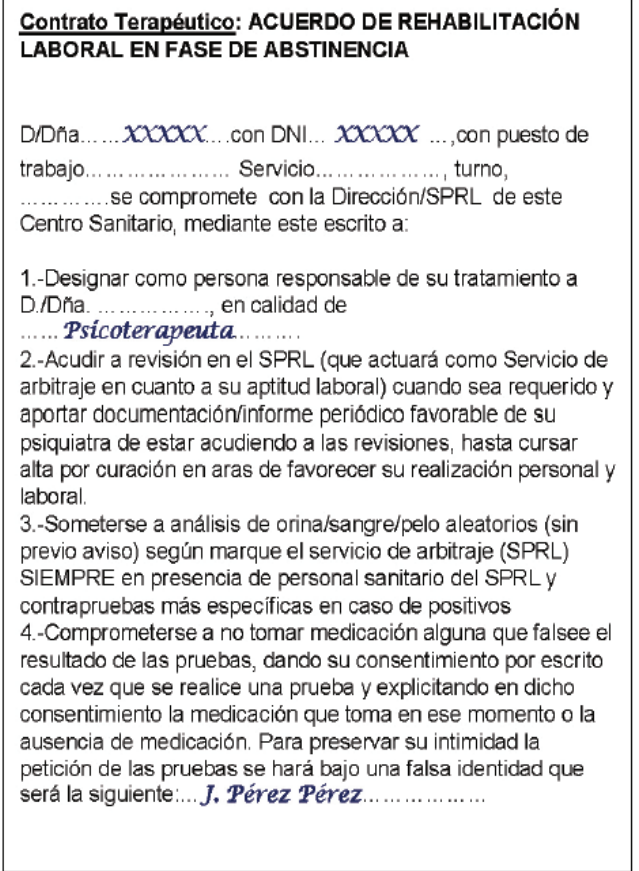

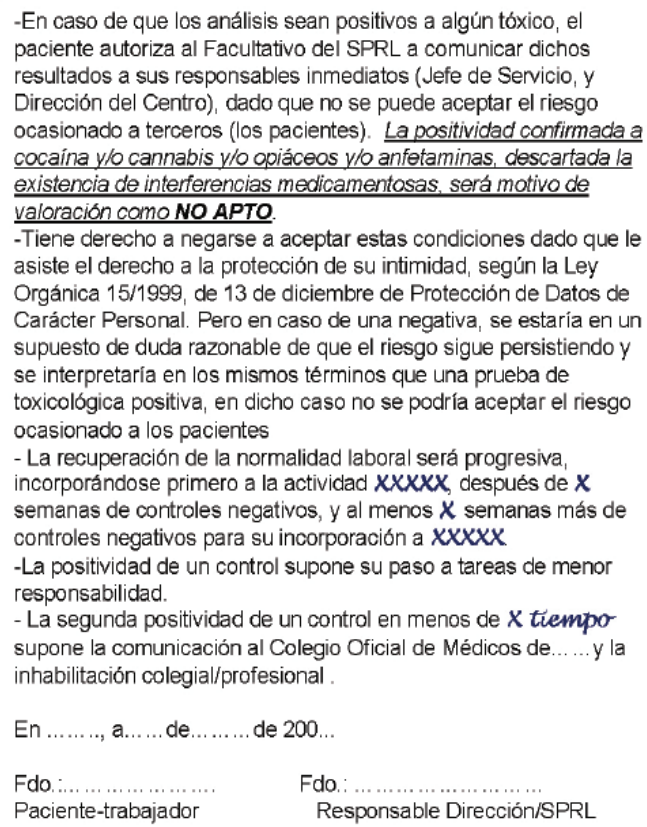

- La recuperación de la normalidad laboral será progresiva incorporándose primero a la actividad $X \times X X X$ después de $X$ semanas de controles negativos, y al menos $X$ semanas más de controles negativos para su incorporación a $X X X X X$

- La positividad de un control supone su paso a tareas de menor responsabilidad.

- La segunda positividad de un control en menos de X tiempo supone la comunicación al Colegio Oficial de Médicos de...... y la inhabilitación colegial/profesional

En ........, a...... de ........ de 200..

Fdo $. . . . . . . \ldots \ldots \ldots . . . . . \quad$ Fdo

Paciente-trabajador Responsable Dirección/SPRL

Fuente: Otero C. Drogodependencias en personal sanitario, una visión desde la medicina del trabajo (II): Procedimiento de reincorporación laboral. 2008.

Figura 5. Reincorporación laboral y procedimiento de seguimiento. Modelo de consentimiento para realizar analíticas y modelo de informe de resultados al trabajador

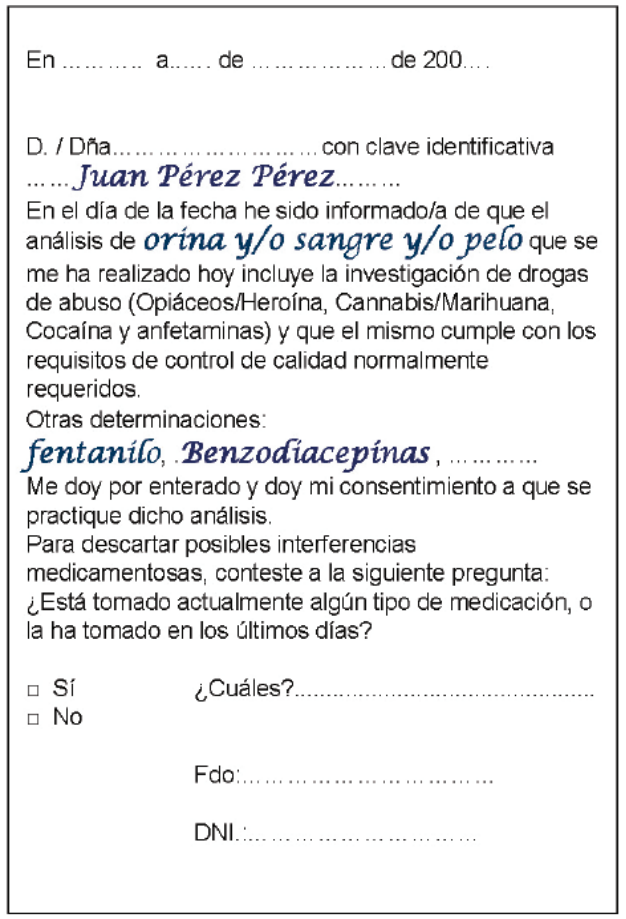

\section{En ............, a..... de ................. de 200 . \\ D. / Dña........................ con clave identificativa Juan Pérez Pérez.}

En el día de hoy he sido informado del resultado de

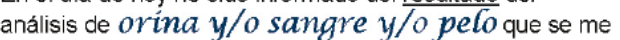
ha realizado el día......... de ....................... de 200 .... para la investigación de drogas de abuso.

Resultado negativo a:

Resultado positivo a:

\section{En caso de positivo:}

Ejerzo / Renuncio (táchese lo que no proceda) el/al derecho a que se practique un contraanálisis y elijo el Laboratorio que cumple con los requisitos de control de calidad normalmente requeridos y asumo los gastos que se deriven de la realización de esta prueba.

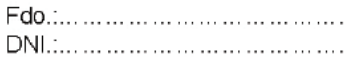

Fuente: Otero C. Drogodependencias en personal sanitario, una visión desde la medicina del trabajo (III): Procedimiento de reincorporación laboral. 2008.

Por último, hay que ser consciente de que, pese al esfuerzo realizado tanto por parte del trabajador como por parte del Médico del Trabajo, puede darse el fracaso del seguimiento. Es necesario hacer una previsión de la posible recaída, así como de la actuación en caso de que se produzca ${ }^{18}$. Revisando los datos de recaídas en personal del 
sector sanitario, se ha contrastado que existe un índice de incidencia de recaída asociado al colectivo de anestesistas que se han reincorporado a su trabajo tras haberse sometido a tratamiento de deshabituación que puede variar desde un $19 \%$ hasta un $\mathbf{4 0} \%$ según diferentes autores ${ }^{38,43}$. Aunque, hasta un $70 \%$ de los profesionales de salud pueden reincorporarse con éxito a su trabajo, después del tratamiento, de los 22 anestesistas que consumieron opioides (fentanilo) como droga de elección en el programa Washington Physicians Health Program (WPHP) sólo 5 pudieron reincorporarse a su trabajo habitual sin ninguna recaída ${ }^{18,43}$. Y el riesgo de recaída fue casi el doble cuando intervino un opioide potente como droga de elección en comparación con otras sustancias de abuso (Hazard Risk (HR) 1.80, IC 1.03-3.13, p = 0.04), o con comorbilidad (asociación de trastorno psicopatológico coexistente con la adicción) (HR 2.12, IC 1.33-3.36, p = 0.02), o con antecedentes familiares del consumo de drogas (HR 2.14, IC 1.18-3.90, p = 0.01) ${ }^{43}$.

Es muy importante determinar la duración del programa de seguimiento. En el estudio del programa WPHP, Domino ${ }^{43}$ demostró que el riesgo de recaída disminuye $(\mathbf{p}<0.001)$ con el incremento en la duración del programa de seguimiento. La tasa de recaída se estimó en 91/1000 personas/año en los dos primeros años del programa, disminuyó a 58/1000 personas/año en los dos a cinco años de programa, y a 32/1000 personas/año después de los cinco años de programa. Según estos datos, se puede estimar que los programas de seguimiento que pretendan evitar o disminuir el riesgo de recaída de los profesionales sanitarios en proceso de recuperación de su adicción deben ser más intensos y prolongados en los sanitarios en los que confluyan varios factores de riesgo o que hayan presentado recaídas previas ${ }^{18}$.

\section{DISCUSIÓN}

La elevada prevalencia del consumo de drogas en el mundo laboral es un reflejo del importante problema de salud pública que representa el consumo de drogas entre la población general, en los países industrializados. En España, en 2008, se encontró una prevalencia de consumo de cannabis en el último año entre la población laboral de un $\mathbf{1 3 . 3 \%}$ en los hombres y de un $7.3 \%$ en las mujeres, y el consumo de cocaína en polvo, evaluada en condiciones similares, fue del $4.7 \%$ en los hombres y $1.8 \%$ en las mujeres. Además, al preguntarles acerca de los riesgos laborales percibidos, se observan mayores prevalencias de consumo de hipnosedantes, cannabis y cocaína entre los trabajadores de ambos sexos que dicen realizar trabajos de mayor peligrosidad o penosidad (perciben elevados riesgos de seguridad). El consumo de drogas ilegales también es más prevalente entre los trabajadores, de ambos sexos, que perciben estar más expuestos a factores de riesgo psicosociales. El elevado consumo entre la población laboral activa ocasiona graves problemas laborales: aumento del absentismo, conflictividad interna en las empresas y accidentabilidad elevada, entre los más importantes (sin contar con otros problemas más difíciles de cuantificar: la disminución de la producción, la baja calidad del producto, el daño moral a la empresa, etc). Los accidentes, no están exentos de responsabilidad, no sólo por el riesgo o daño hacia el propio trabajador accidentado, sino también por los posibles daños ocasionados a terceros. Es en ese momento cuando el problema del trabajador adicto a drogas ilícitas entra dentro del ámbito de actuación de la Prevención de los Riesgos Laborales.

La posibilidad de abordar el problema con éxito desde los servicios de salud laboral de los Servicios de Prevención de las empresas, hacen necesarias la creación de Políticas de Prevención de Drogas en las empresas. Sin embargo, en España, el 99\% de las empresas (excluida la agricultura y la pesca) son pymes, sin recursos ni medios para abordar el problema de las drogodependencias en su ámbito de actuación. Y no son conscientes del problema hasta que surge una situación crítica, de difícil solución: o despido del trabajador, o derivación al Servicio de Prevención Ajeno que suelen tener contratado, sin que nadie sepa muy bien qué hacer. 
Por eso los Médicos del trabajo deben tener pautas concretas de qué hacer ante estas situaciones críticas: cómo abordar problemas de obligatoriedad de exámenes de salud, qué pruebas realizar a los trabajadores según cada circunstancia, cuándo contemplar que un trabajador es especialmente sensible frente a determinados riesgos, en qué ocasiones se pueden solicitar pruebas de detección de drogas y cuándo se está entrometiendo en la intimidad del trabajador, en definitiva, cuáles son las responsabilidades del Médico del Trabajo hacia el problema de las drogodependencias. El Médico del Trabajo deberá:

1. Detectar factores de riesgo (Prevención Primaria) y actuar sobre los mismos: tanto factores de riesgo colectivos (Evaluación de riesgos psicosociales, detección de puestos de trabajo de fácil acceso a psicofármacos, etc.) como factores individuales personales (detección precoz de trabajadores especialmente sensibles (TES), según Art. 25 LPRL). Realizar informes propuesta de adaptación/ cambio de puesto de trabajo, en las situaciones en las que la magnitud del riesgo así lo requiera. También el Médico del Trabajo realizará campañas de promoción de la salud en el lugar de trabajo participando en las estrategias preventivas de formación e información a los trabajadores en materia de drogodependencias.

2. Realizar el diagnóstico precoz en los trabajadores consumidores y/o adictos a sustancias (Prevención Secundaria) y la derivación al SNS para tratamiento de desintoxicación y deshabituación, para lo cual debe conocer qué tipo de exámenes de salud entran dentro de su ámbito de actuación, y qué pruebas complementarias puede solicitar. Protocolo de vigilancia de la salud obligatoria. Coordinación y colaboración con la red asistencial pública.

3. Facilitar la rehabilitación laboral (Prevención Terciaria) favoreciendo la reincorporación laboral del trabajador tras tratamiento de deshabituación, con garantías de seguridad. Si el Médico del Trabajo del SPRL tiene recursos suficientes para abordar el seguimiento de la reincorporación laboral de un trabajador con "alta" laboral y aún en tratamiento de deshabituación, deberá ser durante un período prolongado (aproximadamente en torno a dos años). Se deberá hacer una previsión de costes: costes de recursos humanos (personal sanitario) y materiales (la empresa deberá autorizar los gastos de analíticas toxicológicas, gastos de envío de muestras al laboratorio toxicológico, etc.). El coste moral es difícil de evaluar: para evitar el desgaste de los profesionales que colaboran en el seguimiento (médico del trabajo, responsables inmediatos del trabajador en fase de rehabilitación, compañeros -que tienen que asumir mayor carga de trabajo en tanto que el afectado tiene limitadas algunas tareas, como p.ej. guardias-) es imprescindible tener un procedimiento de actuación al cual ceñirse. Se pueden presentar serios problemas en el seguimiento:

- Existe la posibilidad de obtener falsos negativos pese al cuidado extremo del procedimiento (no se pueden garantizar la detección de consumos esporádicos, ni siquiera con el análisis de pelo).

- Se debe hacer una previsión de recaídas según las condiciones y los riesgos individuales (contemplar esa posibilidad en el "informe de aptitud" al final del proceso).

En cualquier caso, los CDLT han demostrado una gran utilidad para el control de las drogodependencias en las empresas, siempre que sólo sean una herramienta más de un programa integral de prevención de drogodependencias, encuadrado en el marco de una Política de Prevención de Drogas en la empresa, en la que deben implicarse la Dirección, los representantes de los trabajadores (sindicatos y delegados de prevención), y los médicos del trabajo de los Servicios de Prevención, garantizando la confidencialidad y el derecho de intimidad del enfermo, así como el "deber de asistencia" de la organización y el compromiso de reincorporación laboral al puesto de trabajo tras el tratamiento. Trabajando entre todos de forma coordinada, con ética profesional, con respeto a los derechos de los trabajadores, y colaborando con la red pública asistencial para la reincorporación laboral de los trabajadores tratados, conseguiremos, poco a poco, una sociedad más sana. 


\section{REFERENCIAS BIBLIOGRÁFICAS}

1. Progresos en la lucha contra drogas y alcohol en el trabajo. OIT, Revista Trabajo $\mathrm{N}^{\circ}$ 23, Feb. 1998. Disponible en: http://www.ilo.org/public/spanish/bureau/inf/magazine/23/drugs.htm

2. CIT 86 Conferencia Internacional del Trabajo. OIT.1998. http://www.ilo.org/public/spanish/standards/ $\mathrm{relm} / \mathrm{ilc} / \mathrm{ilc} 86 / \mathrm{repi}-\mathrm{c} 3 . \mathrm{htm}$

3. Ley 31/1995, de 8 de noviembre, Ley de Prevención de Riesgos Laborales (BOE $n^{\circ}$ 269, 10-Nov-1995).

4. Estar limpio: controles de consumo de drogas y alcohol en el lugar de Trabajo. OIT. Revista Trabajo No. 57, Sep. 2006. Disponible en: http://www.ilo.org/wow/PlanetWork/lang--es/WCMS_082286/index.htm

5. Ochoa Mangado Enriqueta, Madoz Gúrpide Agustín. Consumo de alcohol y otras drogas en el medio laboral. Med. segur. trab. [Revista en la Internet]. 2008 Dic [citado 2011 Sep 12]; 54(213): 25-32. Disponible en: http:// scielo.isciii.es/scielo.php?script=sci_arttext\&pid=S0465-546X2008000400003\&lng=es.doi:10.4321/S0465546X2008000400003.

6. Encuesta 2007-2008 sobre consumo de sustancias Psicoactivas en el ámbito laboral en España. Observatorio Español sobre Drogas. Ministerio de Sanidad, Política Social e Igualdad, 2011. http:// www.pnsd.msc.es/Categoria2/observa/pdf/Encuesta2007-2008AmbitoLaboral.pdf

7. Portal ELISAD (European Gateway on alcohol, drug and addictions). Disponible en: http://www. addictionsinfo.eu

8. Observatorio Europeo de Drogas y Toxicomanías (OEDT). Disponible en: http://www.emcdda.europa. eu/?nnodeid01596

9. Estrategia Nacional sobre Drogas para el período 2009-2016. Disponible en: http://www.pnsd.msc.es/ novedades/pdf/EstrategiaPNSD2009-2016.pdf

10. Arroyo-Fernández A, García-Sayago F. Valoración médico-legal de las drogas de abuso. Med Clin (Barc). 2006;126(16):632-6.

11. Otero Dorrego C., Huerta Camarero C., Duro Perales N. Drogodependencias en personal sanitario, una visión desde la medicina del trabajo (I): aspectos jurídico-legales y epidemiológicos. Med. segur. trab. [Revista en la Internet]. 2008 Jun [citado 2011 Sep 12]; 54(211): 15-23. Disponible en: http:// scielo.isciii.es/scielo.php?script=sci_arttext\&pid=S0465-546X2008000200003\&lng=es.doi: $10.4321 /$ S0465-546X2008000200003.

12. Ley $5 / 2002$ de 27 de junio, de Drogodependencias y otros trastornos adictivos (BOCM $\mathrm{n}^{\circ} 160,8$-jul-2002 y BOE $n^{\circ}$ 176, 24-jul-2002). Comunidad de Madrid. España.

13. Guía para la mejora de la gestión preventiva. Drogodependencias en el mundo laboral. Confederación empresarial de la provincia de Alicante COEPA, 2003. Disponible en: http://www.coepa.es/prevencion/ guias/_pdf/16_drogodependencia.pdf

14. Plan Nacional sobre Drogas. http://www.pnsd.msc.es

15. Ley Orgánica 15/2007, de 30 de noviembre, por la que se modifica la Ley Orgánica 10/1995, de 23 de noviembre, del Código Penal en materia de seguridad vial. (BOE n ${ }^{\circ} 288$, 1-Dic-2007).

16. Ley Orgánica $1 / 1992$, de 21 de febrero, sobre Protección de la Seguridad Ciudadana (BOE ${ }^{\circ} 46$, 22-Feb-1992).

17. Real Decreto Legislativo $1 / 1995$, de 24 de marzo, por el que se aprueba el texto refundido de la Ley del Estatuto de los Trabajadores (BOE ${ }^{\circ}$ 75, 29-Mar-1995).

18. Otero Dorrego Carmen, Huerta Camarero Carmen, Duro Perales Nuria. Drogodependencias en personal sanitario, una visión desde la medicina del trabajo (II): Procedimiento de reincorporación laboral. Med. segur. trab. [Revista en la Internet]. 2008 Sep [citado 2011 Sep 12] ; 54(212): 7-19. Disponible en: http://scielo.isciii.es/scielo.php?script=sci_arttext\&pid=S0465-546X2008000300002\&lng=es.doi: 10.4321/S0465-546X2008000300002.

19. Las Drogas en el Trabajo. Informe anual 2005: el problema de la drogodependencia en Europa.OMS. Disponible en: http://ar2005.emcdda.europa.eu/es/page014-es.html

20. Edwards CE. Lugares de Trabajo Libres de Drogas. Establecimiento de una Política y Programa. Oficina para la Reducción de la Demanda del Tráfico de Drogas en Áreas de Alta Intensidad (H.I.D.T.A), Arizona, USA. 2004. Disponible en: http://www.drugwatch.org/reports/DFWWorkPlaceManualSpan.pdf

21. Cómo prevenir los riesgos derivados del consumo indebido de alcohol y otras sustancias en el ámbito laboral. Confederación Empresarial Vasca (CONFEBASK). 2004. Disponible en: http://www.lineascen. cenavarra.es/documentos/ficheros_recursos/Drogas.pdf

22. Guía de intervención sindical sobre drogodependencias en el ámbito laboral. CCOO 2005. Disponible en: http://www.ccoomadrid.es/comunes/temp/recursos/14/464996.pdf

23. Orientaciones sobre intervención sindical en drogodependencias. Ed. Secretaría Confederal de Salud Laboral CCOO. Tercera ed. Revisada 2009. Disponible en: http://www.pnsd.msc.es/Categoria2/publica/ otras.htm y en http://www.ccoo.es/comunes/temp/recursos/1/617781.pdf 
24. Prevención de adicciones en los trabajadores de instituciones penitenciarias. Secretaría de salud laboral de UGT (2010). Disponible en: http://www.pnsd.msc.es/Categoria2/publica/otras.htm y en http://www. ugt.es/saludlaboral/FolletoAdicciones\%20(2).pdf

25. Manual de Procedimientos Operativos de Prevención. P.O.P/09. Vigilancia de la salud. RENFE. Disponible en: http://www.sff-cgt.es/salud_laboral/Procedimiento\%20Operativos/POP\%2009\%20 Vigilancia\%20de\%201a\%20Salud/pop9.pdf

26. Retrato de la pyme 2010. Ministerio de Industria, Turismo y Comercio. España.2010. Disponible en: http://www.ipyme.org/Publicaciones/Retrato\%20PYME\%202010.pdf

27. Martínez Fons D. Intimidad y vigilancia de la salud del trabajador en la relación de trabajo (Iberia). Comentario a la STCO 196/2004. UPF. Barcelona. 2005. Disponible en: http://www.upf.edu/ iuslabor/022005/art04.htm

28. Ley Orgánica 15/1999, de 13 de diciembre, de Protección de Datos de Carácter Personal. de Protección de Datos (LOPD) (BOE no 298, 14-Dic-1999). http://www.boe.es/boe/dias/1999/12/14/pdfs/A4308843099.pdf

29. Ley $41 / 2002$, de 14 de noviembre, básica reguladora de la autonomía del paciente y de derechos y obligaciones en materia de información y documentación clínica (BOE $\left.{ }^{\circ} 274,15-N o v-2002\right)$.

30. Mingote Adán José Carlos, Pino Cuadrado Pablo del, Gálvez Herrer Macarena, Gutiérrez García M. ${ }^{a}$ Dolores, Sánchez Alaejos Raquel. Utilidad preventiva del constructo "trastorno mental grave" en el ámbito sociosanitario. Med. segur. trab. [revista en la Internet]. 2010 Dic [citado 2011 Sep 26] ; 56(221): 306-322. Disponible en: http://scielo.isciii.es/scielo.php?script=sci_arttext\&pid=S0465-546X2010000400006\&lng=es. doi: 10.4321/S0465-546X2010000400006.

31. Ley $1 / 2000$, de 7 de enero, de Enjuiciamiento Civil (BOE $n^{\circ} 7,8$-Ene-2000). http://www.boe.es/boe/ dias/2000/01/08/pdfs/A00575-00728.pdf

32. RD 39/1997, de 17 de enero, por el que se aprueba el Reglamento de los Servicios de Prevención (BOE n ${ }^{\circ}$ 27, 31-En-1997).

33. NTP 443. Factores Psicosociales: metodología de evaluación. INSHT. 2001. http://www.insht.es/ InshtWeb/Contenidos/Documentacion/FichasTecnicas/NTP/Ficheros/401a500/ntp_443.pdf

34. Otero Dorrego C, Duro Perales N, Cornejo García I, Miquel Gómez A, Mayol Canas J. Antes y Después De La Evaluación De Riesgos Psicosociales En El Ámbito Sanitario. VI Jornadas y II Congreso Nacional de los Servicios de Prevención de Riesgos Laborales en el Ámbito Sanitario 12, 13 y 14 de Noviembre de 2008. Madrid. Disponible en: http://sprlarea11madrid.es/jornadas_congresos/ii_congreso/doc/P10.pdf

35. Procedimiento General de Evaluación de Riesgos Psicosociales. Grupo de trabajo de la Comisión sobre factores de riesgo psicosocial en el trabajo. Instituto Navarro de Salud Laboral. 2005. Pamplona. Disponible en: http://www.navarra.es/NR/rdonlyres/54675C79-A455-4B62-B714E9200642BF83/145962/ProcedEvalRiesgosPsico.pdf

36. Cornejo I, Otero C, González A, Pérez J, Hernández A, Fernández R. Diseño y realización de un Análisis de Riesgos Psicosociales en Atención Primaria. P039. 25 Congreso de la Sociedad Española de Calidad Asistencial. Barcelona. 16 $\otimes 19$ Octubre 2007. Disponible en: http://www.calidadasistencial.es/images/ gestion/congresos_pdf/15.pdf

37. Calabrese G. Fármaco-dependencia en anestesiólogos, un gran problema ocupacional actual. Rev. Col. Anest., June 2006, vol.34, no.2, p.103-111. ISSN 0120-3347.

38. Gold MS, Melker RJ, Dennis DM, Morey TE, Bajpai LK, Pomm R, Frost-Pineda K. Fentanyl abuse and dependence: further evidence for second hand exposure hypothesis. J Addict Dis. 2006;25(1):15-21.

39. McAuliffe PF, Gold MS, Bajpai LK, Merves ML, Frost-Pineda K, Pomm R, Goldberger BA, Melker RJ, Cendan JC. Second-hand exposure to aerosolized intravenous anesthetics propofol and fentanyl may cause sensitization and subsequent opiate addiction among anesthesiologists and surgeons. Med Hypotheses. 2006;66(5):874-82. Epub 2006 Jan 23.

40. Talbott G, Gallegos K, Wilson P, Porter T. The Medical Association of Georgia's impaired physicians program. Review of the first 1000 physicians: analysis of specialty. JAMA 1987;257:2927-30.

41. Wolf K, Farrel M, Marsden J, Monteiro MG, Ali R, Welch S, et al. Revisión de los indicadores biológicos de uso ilegal de drogas, consideraciones prácticas y utilidad clínica. RET, Revista de Toxicomanías. $\mathrm{N}^{\circ}$ 28, 2001.

42. G Zapater, MJ Perea, C Carrizosa, B Bravo, LJ Segura. Estudio de 156 casos de accidentes laborales mortales en la Comunidad de Madrid. Análisis de alcohol etílico y otras sustancias psicoactivas. TF-C13. Rev. Toxicolo (2003) 20. XV Congreso Español de Toxicología.

43. Domino KB, Hornbein TF, Polissar NL, Renner G, Johnson J, Alberti S, Hankes L: Risk Factors for Relapse in Health Care Professionals with Substance Use Disorders. JAMA. 2005 Mar 23/30; 293(12):1453-60.

|l||||||||||||||||||||||||||||||||||||||||||||||||||||||||||||||||||||||||||||||||||||||||||||||||||||||||||||||||||||||||||||||||||||||||||||||||||||||||||||||||||||||||||||||||||||||||||||||||||||||||||| 